\title{
Will Electric Cars Transform the U.S. Market
}

\section{Citation}

Lee, Henry, and Grant Lovellette. 2011. Will Electric Cars Transform the U.S. Market? HKS Faculty Research Working Paper Series RWP11-032, John F. Kennedy School of Government, Harvard University.

\section{Published Version}

http://web.hks.harvard.edu/publications/workingpapers/citation.aspx?Publd=7926

\section{Permanent link}

http://nrs.harvard.edu/urn-3:HUL.InstRepos:5116458

\section{Terms of Use}

This article was downloaded from Harvard University's DASH repository, and is made available under the terms and conditions applicable to Other Posted Material, as set forth at http:// nrs.harvard.edu/urn-3:HUL.InstRepos:dash.current.terms-of-use\#LAA

\section{Share Your Story}

The Harvard community has made this article openly available.

Please share how this access benefits you. Submit a story.

Accessibility 


\section{Will Electric Cars Transform the U.S. Market? \\ Faculty Research Working Paper Series}

\section{Henry Lee}

Harvard Kennedy School

\section{Grant Lovellette}

Harvard Kennedy School

\section{August 2011 RWP11-032}

The views expressed in the HKS Faculty Research Working Paper Series are those of the author(s) and do not necessarily reflect those of the John F. Kennedy School of Government or of Harvard University. Faculty Research Working Papers have not undergone formal review and approval. Such papers are included in this series to elicit feedback and to encourage debate on important public policy challenges. Copyright belongs to the author(s). Papers may be downloaded for personal use only. 


\section{ENERGY TECHNOLOGY INNOVATION POLICY RESEARCH GROUP}

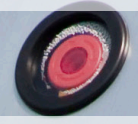

\section{WILL ELECTRIC CARS TRANSFORM THE U.S. VEHICLE MARKET?}

AN ANALYSIS OF THE KEY DETERMINANTS BY HENRY LEE AND GRANT LOVELLETTE
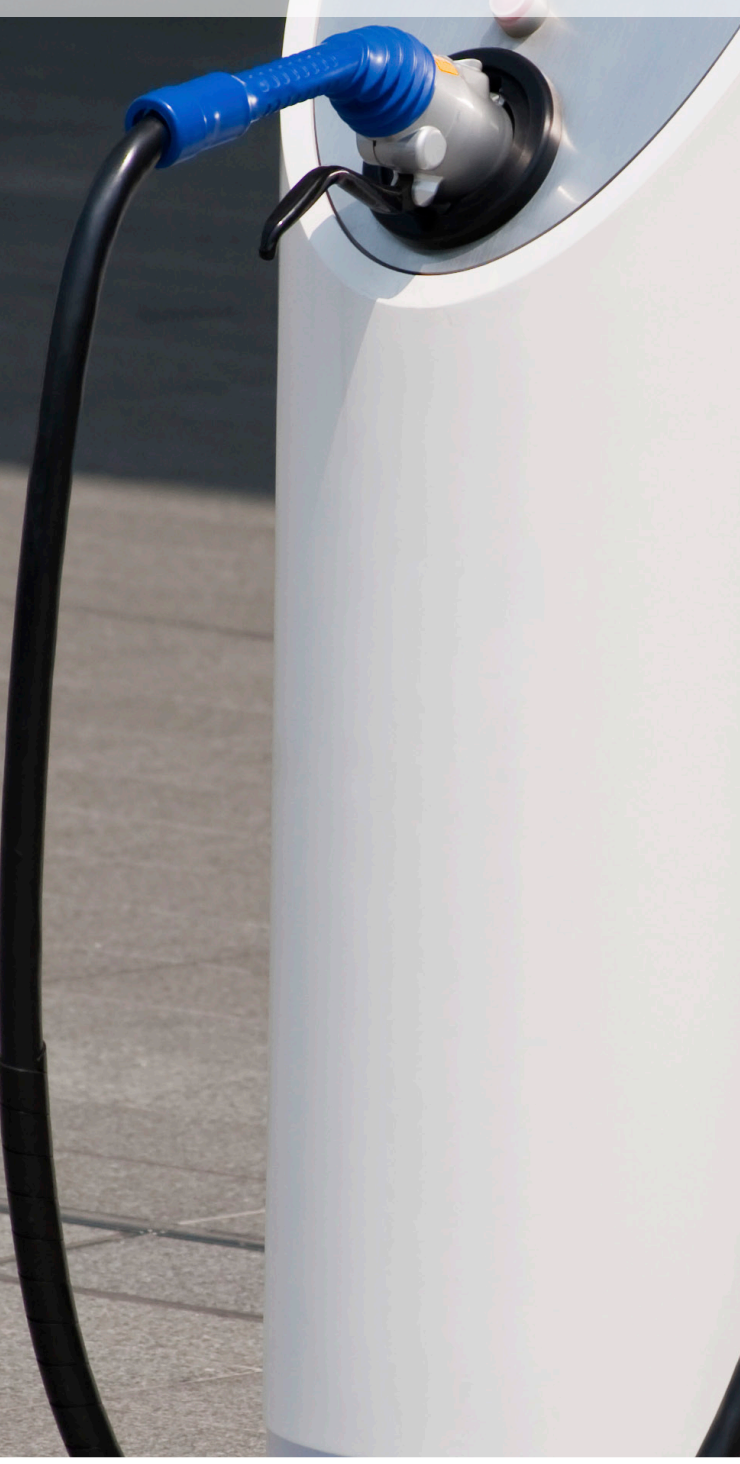
Discussion Paper \#2011-08

Energy Technology Innovation Policy Discussion Paper Series

\section{Belfer Center for Science and International Affairs}

Harvard Kennedy School

79 JFK Street

Cambridge, MA 02138

Fax: (617) 495-8963

Email: belfer_center@harvard.edu

Website: http://belfercenter.org

Copyright 2011 President and Fellows of Harvard College 


\title{
Will Electric Cars Transform the U.S. Vehicle Market?
}

\section{An Analysis of the Key Determinants}

\author{
By Henry Lee* and Grant Lovellette ${ }^{\dagger}$
}

\author{
Energy Technology Innovation Policy \\ Belfer Center for Science and International Affairs \\ Harvard Kennedy School, Harvard University \\ 79 John F. Kennedy Street \\ Cambridge, MA 02138 \\ USA
}

Belfer Center Discussion Paper 2011-08

July 2011

\footnotetext{
* Director, Environment and Natural Resources Program; Co-Principal Investigator, Energy Technology Innovation Policy research group; Senior Lecturer in Public Policy, Harvard Kennedy School.

${ }^{\dagger}$ Principal Researcher, Masters in Public Policy 2010, Harvard Kennedy School.
} 


\section{Citation}

This paper may be cited as: Lee, Henry and Lovellette, Grant, "Will Electric Cars Transform the U.S. Vehicle Market? An Analysis of the Key Determinants,” Discussion Paper 2011-08, Cambridge, Mass.: Belfer Center for Science and International Affairs, July 2011.

Comments are welcome and may be directed to Henry Lee at the Belfer Center for Science and International Affairs, Harvard Kennedy School, Harvard University, 79 JFK Street, Cambridge, MA 02138, henry_lee@harvard.edu. This paper is available at belfercenter.org/energy.

\section{DISCLAIMER}

The views expressed within this paper are the authors' and do not necessarily reflect those of the organizations they are affiliated with, its members, nor any employee or persons acting on behalf of any of them. In addition, none of these make any warranty, expressed or implied, assumes any liability or responsibility for the accuracy, completeness or usefulness of any information, apparatus, product or process disclosed or represents that its use would not infringe privately owned rights, including any party's intellectual property rights. References herein to any commercial product, process, service or trade name, trade mark or manufacturer does not necessarily constitute or imply any endorsement, or recommendation or any favoring of such products. 


\section{Energy Technology InNovation Policy (ETIP)}

The overarching objective of the Energy Technology Innovation Policy (ETIP) research group is to determine and then seek to promote adoption of effective strategies for developing and deploying cleaner and more efficient energy technologies, primarily in three of the biggest energy-consuming nations in the world: the United States, China, and India. These three countries have enormous influence on local, regional, and global environmental conditions through their energy production and consumption.

ETIP researchers seek to identify and promote strategies that these countries can pursue, separately and collaboratively, for accelerating the development and deployment of advanced energy options that can reduce conventional air pollution, minimize future greenhouse-gas emissions, reduce dependence on oil, facilitate poverty alleviation, and promote economic development. ETIP's focus on three crucial countries rather than only one not only multiplies directly our leverage on the world scale and facilitates the pursuit of cooperative efforts, but also allows for the development of new insights from comparisons and contrasts among conditions and strategies in the three cases. 


\section{ACKNOWLEDGEMENTS}

We would like to thank Robert Frosch, Sarah Jordaan, Richard Zeckhauser, Erich Muehlegger, and William Hogan for their helpful comments and insights. Eric Lu was enormously helpful in finding data and information. Amanda Swanson oversaw the formatting and publication. We are especially grateful to Ashley Gagné for her patience and help in editing and preparing the manuscript.

We also appreciate the encouragement and insights from the U.S. Department of Energy, the Environmental Protection Agency, Nissan Motors, Exxon, and the Alliance of Automobile Manufacturers. The analysis and findings, however, contained in this manuscript are entirely those of the two authors and do not necessarily represent those of the people, agencies, or companies who gave so generously of their time. 


\section{EXECUTIVE SUMMARY}

For the past forty years, United States Presidents have repeatedly called for a reduction in the country's dependence on fossil fuels in general and foreign oil specifically. Stronger efficiency standards and higher taxes on motor fuels are a step in this direction, but achieving even greater reductions in oil consumption will require changing the way Americans power their transportation system. Some officials advocate the electrification of the passenger vehicle fleet as a path to meeting this goal. The Obama administration has, for example, embraced a goal of having one million electric-powered vehicles on U.S. roads by 2015, while others proposed a medium-term goal where electric vehicles would consist of $20 \%$ of the passenger vehicle fleet by 2030 - approximately 30 million electric vehicles.

The technology itself is not in question-many of the global automobile companies are planning to sell plug-in hybrid electric vehicles (PHEVs) and/or battery electric vehicles (BEVs) by 2012. The key question is, will Americans buy them?

The answer depends on four additional questions: 1 . Is the cost of purchasing and operating an electric vehicle more or less expensive than the cost of a comparable conventional gasolinepowered vehicle? 2. Are the comparative costs likely to change over the next twenty years? 3. Do electric vehicles provide the same attributes as conventional cars, and if not, do the differences matter? 4. Will electric car owners be able to access the electricity needed to power their vehicles?

This paper attempts to answer these four questions.

There are two basic categories of electric vehicles-electric vehicles (BEVs), which run solely on the electric energy stored in the battery, and plug-in hybrid electric vehicles (PHEVs), which operate on both a rechargeable battery and a gasoline-powered engine. With both types of vehicles, the major incremental expense compared to a conventional vehicle is the cost of the battery. While the industry is working hard to reduce these costs, a battery in a BEV with an average range of $60-80$ miles costs between $\$ 10,000$ and $\$ 15,000$. Hence, this paper compares the net present lifetime cost of electric vehicles with that of conventional cars, both at today's costs and at projected future costs. The paper also runs comparison scenarios with different assumptions about gasoline and electricity costs, battery costs, consumer discount rates, and vehicle efficiency levels. 


\section{Costs}

This paper finds that, at 2010 purchase and operating costs, a PHEV-40 is \$5,377 more expensive than an internal combustion engine or ICE, while a BEV is $\$ 4,819$ more expensive. In other words, the gasoline costs savings of electric cars over the cars' lifetimes will not offset their higher purchase prices.

In the future, this cost balance may change. If one assumes that over the next 10 to 20 years battery costs will decrease while gasoline prices increase, BEVs will be significantly less expensive than conventional cars $(\$ 1,155$ to $\$ 7,181$ cheaper). Even when the authors use very high consumer discount rates, BEVs will be less expensive, than conventional vehicles although the cost difference decreases. PHEVs, however, will be more expensive than BEVs in almost all comparison scenarios, and only less expensive than conventional cars in a world with very low battery costs and high gasoline prices. BEVs are simpler to build and do not use liquid fuel, while PHEVs have more complicated drive trains and still have gasoline-powered engines.

\section{Will Consumers Purchase Electric Vehicles?}

Consumers purchase cars based on how they value multiple attributes. They care about performance, aesthetics, reliability, and many other features. Cost is an important consideration, but not the only one. Electric vehicle manufacturers have worked hard to ensure that electric cars are comparable over a wide range of attributes, but BEVs are plagued by limited range (the number of miles they can be driven before they need to be recharged), and consumers remain worried about the reliability of both BEVs and PHEVs relative to conventional vehicles. The latter problem will gradually disappear as motorists become more accustomed to electric cars, but range anxiety is likely to remain until battery technology improves. One can argue that such anxiety is irrational, since urban drivers, on average, drive less than 20 miles per day, but no one has ever asserted that consumers base their car purchases solely on rational calculations. One might contend that the value of greater range is (approximately) the $\$ 4,000$ price premium consumers will pay for a PHEV over a BEV, according to our model. Regardless, the bottom line is that the range issue will significantly affect consumer choice and is a major barrier to the penetration of electric vehicles. 


\section{Is the Electrical Infrastructure Available?}

To power an electric vehicle, consumers must have the ability to connect their vehicle to a source of electricity, the utility must have the capacity to transmit and distribute this additional power and sufficient electricity generation capacity must exist. If the private sector is unwilling to meet these three conditions (i.e. providing 1. charging equipment, 2. distribution capacity, and 3. electricity generation), then governments must intervene. However, this paper finds no clear market failure that would require or justify such interventions.

The charging equipment is not expensive, and it would not be difficult for households and commercial enterprises to install such equipment. The adequacy of the distribution and generation systems will differ from one state to the next, and the electric utility industry will have the ability and time to make the necessary investments to keep up with the increasing demand from electric vehicles. Private industry may not be willing to invest well ahead of demand, but it is not clear that building swaths of underused public charging stations is the optimal way to subsidize and accelerate the purchase of electric vehicles.

\section{Can the United States Meet its Electric Vehicle Goals?}

Significant penetration of electric vehicles can only occur if American consumers decide to forego purchasing gasoline-powered cars and opt to buy electric vehicles. For this to happen on a large-enough scale to make a difference in oil consumption or pollution emissions, electric cars must be competitive with conventional cars across a wide range of attributes, including total costs (purchase, operations, and maintenance) and range. For this scenario to occur, gasoline prices will have to increase to $\$ 4.50-\$ 5.50$ per gallon, and battery technology will have to improve significantly, providing increased range at decreased cost. Both scenarios are possible. Government assistance in the form of continued support for research and demonstration of new battery technologies and a willingness by Congress to place a cost on oil imports and conventional and unconventional air pollutants would accelerate this process. 


\section{TABLE OF CONTENTS}

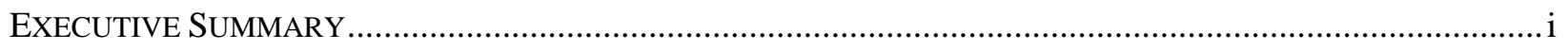

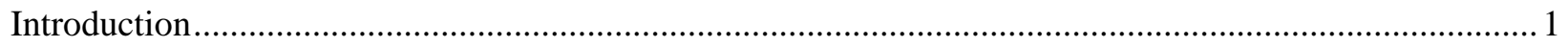

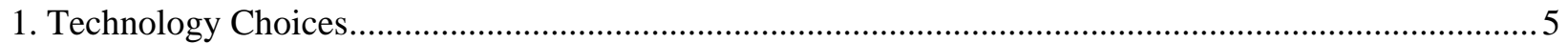

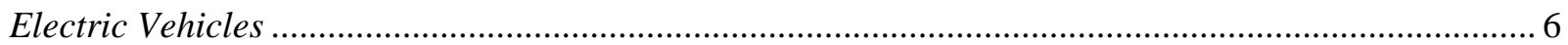

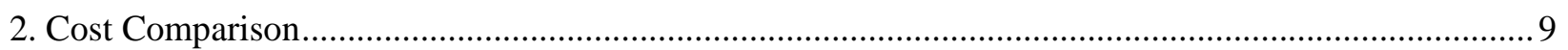

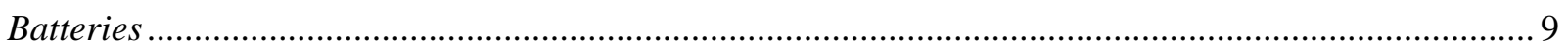

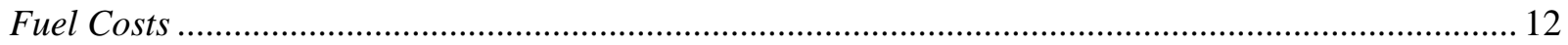

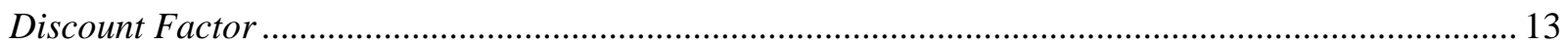

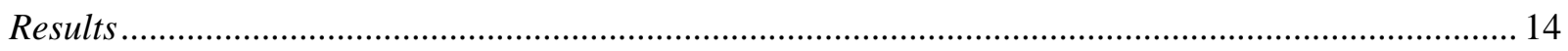

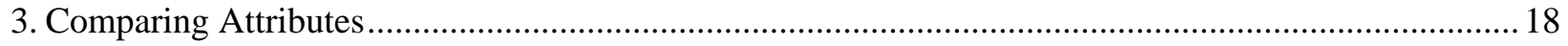

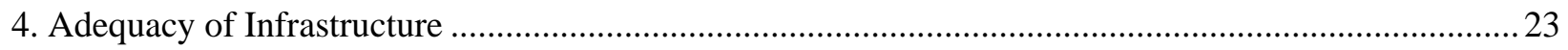

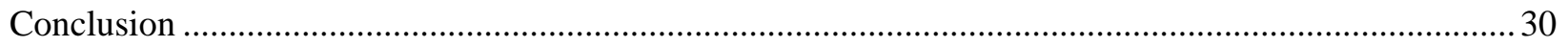

Appendix A: Cost Model at Current Energy Prices................................................................................... 33

Appendix B: Monte Carlo Simulation and Sensitivity Analysis ............................................................... 34 


\section{Introduction}

Spurred by concerns over conventional and unconventional air emissions and the availability of future oil supplies, government officials in the United States, China, and Europe have embraced electric vehicles as a zero emission alternative to gasoline-powered vehicles. In fact, the Obama administration has set an ambitious goal of having one million electric cars on the road by 2015. ${ }^{1}$ Echoing this optimism, many major automobile companies have, or will have, versions of the electric car in their showrooms by the end of 2012. Nissan Motors is placing a six billion dollar bet that there will be a growing market for such vehicles, and Congress has enacted generous subsidies to encourage their production and adoption.

Proponents tout electric vehicles as a potential solution to many problems. To those worried about the United States’ continued reliance on imported oil, the electric car promises to reduce oil consumption and enhance U.S. energy security. To those worried about climate change, electric cars, especially in a grid powered increasingly by renewable energy, could reduce greenhouse gas emissions. To those worried about the United States' competitive position in a world seeking green technologies, electric vehicles could stimulate jobs in industries ranging from batteries to smart grids to the vehicles themselves. Finally, to states and municipalities that are struggling to meet ever more stringent standards for conventional air emissions, such as small particles and nitrogen dioxide, electrifying the transport sector may enable their communities to meet new, tougher emissions standards. These combined interests may form a potent constituency pushing for greater electrification.

After careful analysis, each of these perceptions may seem optimistic, but several trends exist that cannot be ignored. As emerging markets such as China and India enjoy increases in per capita incomes, world demand for passenger vehicles will grow. The United States had about 256 million highway-registered vehicles in 2008, ${ }^{2}$ while China has about 128 million private motor vehicles, ${ }^{3}$ and India has more than 40 million. ${ }^{4}$ This will change over the next twenty

\footnotetext{
1 "Vice President Biden Announces Plan to Put One Million Advanced Technology Vehicles on the Road by 2015." News. Department of Energy. January 26, 2011. Accessed online at http://www.energy.gov/news/10034.htm.

2 “Table 1-11: Number of U.S. Aircraft, Vehicles, Vessels, and Other Conveyances.” National Transportation Statistics. Accessed online at http://www.bts.gov/publications/national_transportation_statistics/html/table_01_11.html.

3 “168 mln motor vehicles on China's roads, up 5\% year-on-year,” XinhuaNet. Accessed online at http://news.xinhuanet.com/english/2008-10/08/content_10166911.htm.
} 
years. In 2010, there were about 750 million passenger vehicles in the world, and by 2030, this number is predicted to grow to 1.1 billion. By 2050, it could be as high as 1.5 billion. It would be unrealistic to assume that a passenger fleet of this size will only be populated by gasolinepowered vehicles. One would have to assume either that the global transportation fleet will be twice as efficient in 2050 as it is today, or that the world's oil supply will be sufficient to meet the demand of a fleet that is twice as large.

The U.S. House of Representatives, the President, and numerous state governments have set greenhouse gas reduction goals for the 2040-2050 time period of 60\%-80\% below 2005 levels. One can argue that these goals are too ambitious or even unrealistic. Nevertheless, if the U.S. aims to realize them, must change how it fuels its transportation sector, since this sector accounted for about $27 \%$ of total U.S. greenhouse gas emissions in 2008 and has been the fastest-growing source of U.S. greenhouse gas emissions since $1990 .^{5}$

Finally, if U.S. policymakers decide to promote reduced oil consumption, they must contend with the fact that $70 \%$ of the oil consumed in the United States is used for transportation, and of the oil used for transportation, about $70 \%$ is consumed by passenger vehicles. A strategy of reducing oil consumption that does not involve significant reductions in gasoline demand will not be effective.

In the past three years, many studies, papers, and reports have examined various promises and challenges of introducing electric vehicles into the U.S. automobile fleet-including environmental impacts, impacts on the electrical grid, and economic costs. They have looked at a vast range of future technologies, both for the vehicle itself and for the components of the vehicle, especially the battery. The purpose of this paper is more limited —we pose the question, under what circumstances is the United States likely to see large-scale adoption of electric vehicles over the next twenty-five years? What factors might influence a significant number of consumers to purchase or reject electric vehicles?

An easy answer is that it depends on the cost of electric vehicles as opposed to the cost of conventional vehicles. However, this leads to the question - the cost to whom? Inherently, the public and private sectors will share the costs. The U.S. government presently provides a subsidy

\footnotetext{
4 “India Car Sales Touch Record High.” Article. The Wall Street Journal Digital Network. September 9, 2010. Accessed online at http://online.wsj.com/article/SB10001424052748703453804575480881344386638.html.

5 "Basic Information: Greenhouse Gas Emissions from Transportation." United States Environmental Protection Agency. September 14, 2010. Accessed online at www.epa.gov/oms/climate/basicinfo.htm.
} 
of up to $\$ 7,500$ per electric vehicle. ${ }^{6}$ Hence, a $\$ 40,000$ vehicle costs the consumer $\$ 32,500$, and the taxpayer is paying the $\$ 7,500$ difference. The Electric Vehicle Deployment Act would, if passed, increase this subsidy to $\$ 9,500$ for the first 100,000 electric vehicles sold in selected deployment communities. ${ }^{7}$ Theoretically, consumers and producers may split the subsidy, but in this case, almost all of it is passed onto consumers. The Electrification Coalition has written a report requesting Congress to enact a series of subsidies that they estimate will cost $\$ 121$ billion between now and $2018^{8}$ (though we find their estimate of the costs of the subsidies they propose to be rather conservative). The rationales for this request are that the EV industry is unlikely to develop rapidly without government assistance and that most of the benefits of electric cars accrue to society generally, so it is appropriate for taxpayers to pay for these benefits.

In addition, electric utilities in some regions will be asked to add additional generation capacity and to upgrade their distribution system. Will this cost be assumed by all ratepayers, or will public utility commissions identify mechanisms whereby those who benefit pay-i.e. will only the owners (or prospective owners) of electric vehicles pay the additional cost? This issue becomes even more complicated when one contemplates the introduction of smart grid technologies that will have the capability to stagger the charging of electric vehicles throughout the evening and night, thus optimizing the use of the grid. Under some scenarios, the electricity stored in the vehicles could be sold back to the grid to meet peak demand.

In summary, the public and the private sectors will share the costs of transitioning to electric vehicles. The size of these costs could be large, and there has been no rigorous attempt to devise guidelines or principles on how this division should be made. At minimum, the public sector should calculate the benefits and costs of promoting the transition to electric vehicles. How large are the energy security benefits? How great are the benefits to U.S. competitiveness? How significant are the environmental benefits to the country? Is the cost to the public of stimulating this transition equal to, less than, or greater than the benefits?

Identifying and valuing both public and private benefits and costs will be an ongoing challenge, as both the total costs and the technologies evolve. At the moment, the government is providing subsidies without any real effort to estimate the value of the benefits that the subsidies

\footnotetext{
6 "Plug-In Electric Vehicle Credit (IRC 30 and IRC 30D).” Internal Revenue Code 30 and 30D. IRS. May 24, 2011. Accessed online at http://www.irs.gov/businesses/article/0,id=214841,00.html.

${ }^{7}$ Motavalli, Jim. “Electric Car Group Looks for Legislative Boost.” The New York Times. June 23, 2010.

${ }^{8}$ Electrification Coalition, “Economic Impact of the Electrification Roadmap," p. 10. April 2010. Accessed online at http://www.electrificationcoalition.org/sites/default/files/SAF_1249_EC_ImpactReport_v06_proof.pdf.
} 
will generate. Is subsidizing electric cars a cost-effective option to reduce greenhouse gases? What are the energy security benefits of substituting one million gasoline vehicles with one million electric vehicles? How many incremental jobs are actually created if American consumers replace their gasoline-powered vehicles with electric substitutes, and at what cost per job?

From the private perspective, the analytic process is identical. What are the benefits to the consumer of purchasing an electric vehicle? The answer will be very different in a world of $\$ 3$ per gallon gasoline as opposed to a world of $\$ 6$ per gallon gasoline. Furthermore, the market will reward consumers for consuming less oil, since the higher the price of oil, the lower the need for public expenditures. Hence, the division of costs between the public and private sectors will be heavily influenced by expected oil prices.

Moreover, what private benefits will attract consumers to purchase electric cars? Alternatively, are most of the benefits in electrifying the passenger car fleet generated in the forms of positive externalities derived and negative externalities avoided? Only a small minority of Americans are likely to be willing to pay a several thousand dollar premium in order to be perceived as greener than their neighbors. In terms of storage, range, and reliability, today's conventional gasoline-powered vehicles are perceived as superior to electric vehicles. Hence, most of the incremental costs to spur the penetration of electric vehicles, at least in the near-term, are likely to fall on the public sector. Certainly, technologies can improve. Batteries may become cheaper and lighter, and charging equipment can become more versatile; but these improvements are still developing.

Theoretically, values can change. Americans may decide to value small electric vehicles as second cars for commuting to work or picking children up from school. However, history has shown that changing consumer preferences is often a daunting task.

We begin this paper by defining what we mean by the term "electric car." We analyze the costs in comparison with both conventional internal combustion engines (ICE) cars and hybrid cars over a broad spectrum of assumptions. Costs are only one of many attributes by which consumers compare vehicles. Range, reliability, performance, and style are weighed as well. We assess how these additional attributes may affect consumer choice. We then identify the issues surrounding the infrastructure needed to charge electric vehicles. In the final section, we make some preliminary recommendations. 


\section{Technology Choices}

If the goal is to reduce gasoline consumption in the passenger vehicle sector significantly, there are three basic options_reducing vehicle miles traveled, improving the efficiency of the fleet, and substituting other forms of energy for gasoline. Studies have shown that gasoline prices would have to rise to very high levels before they would result in considerable reductions in driving. ${ }^{9}$ The United States has adopted more ambitious efficiency standards for new vehicles, but the 2016 standard of 36 miles per gallon would have to double to meet the carbon and oil consumption goals set by the Obama administration. This may be feasible, but the technologies to achieve such a goal without major reductions in vehicle size and performance have yet to materialize.

The final option is to develop and use substitute fuels. These might include compressed natural gas (CNG), hydrogen, biofuels, or electricity. This paper will only focus on electricity, using projections for improvements in the efficiency of internal combustion engine vehicles (including hybrid electric cars) as points of comparison. With the prospect of a growing differential between the price of gasoline and natural gas, there is a growing interest in the use of CNG as a substitute for gasoline. Interestingly, this option will face many of the same problems confronting electric cars-high initial costs, the need to build a new fuel infrastructure, and limited range. An analysis comparing the economics and attributes of electric and CNG-powered vehicles would be valuable, but is outside the scope of this paper.

Each of these three options to reduce gasoline consumption suffers from major practical and/or institutional constraints. Reducing VMT involves significantly increasing the price of gasoline or the price of accessing the highways. Improving efficiency requires either substantial government intervention into the car market or that consumers change their purchasing behavior. Changing fuels will require developing new infrastructure to provide these alternative fuels. All these options are fraught with political and economic challenges. Unfortunately, in the energy sphere, there are many more examples of failed technological or programmatic initiatives than successes. It is also true, however, that policies that are politically unacceptable or economically irrational today might be feasible tomorrow.

\footnotetext{
${ }^{9}$ Morrow, W. Ross, Kelly Sims Gallagher, Gustavo Collantes, and Henry Lee. “Analysis of Policies to Reduce Oil Consumption and Greenhouse-Gas Emissions from the US Transportation Sector.” Energy Policy 38, no. 3 (March 2010): 1305-1320.
} 
Mandates for non-gasoline fueled vehicles only apply to new vehicles; thus, it would take a decade or more to alter the vehicle fleet. If people started buying significant numbers of nongasoline-fueled vehicles in 2016, the country would not see the full result until after 2030. Even this scenario may be optimistic, since not all consumers will purchase the electric car or even the more efficient ICE, if they are significantly more expensive than an older used car. Instead, they may hold onto their less efficient cars, hoping to extend their useful life.

\section{Electric Vehicles}

What is an electric vehicle (EV)? There are several varieties. The two most common are battery electric vehicles (BEVs) and plug-in hybrid electric vehicles (PHEVs), and there are several varieties of the latter. For the sake of this paper, a conventional hybrid (HEV), such as a Toyota Prius, which is capable of drawing some of its energy from an electric battery, but not from the electric grid, will not be considered an electric vehicle.

BEVs run solely on chemical energy stored in rechargeable electric battery packs. They have a theoretical average range of around 100 miles (though some BEVs have ranges of up to 250 miles), and their performance can mirror that of a conventional vehicle.

BEVs have existed since the birth of the American automobile industry. In fact, at the dawn of the twentieth century, consumers could choose between three different propulsion technologies: 1. a steam powered internal combustion engine, which was fast and inexpensive, but required a long time to start and had to be refilled with water every few miles; 2 . a gasoline powered engine (ICE), which was dirtier, even more difficult to start, but could travel long distances quickly and without refueling, and 3 . a vehicle with an electric motor, which was quiet and clean, but slow and expensive.

Henry Ford and Thomas Edison were friends, and Ford was very attracted to the electric option, but opted to go with the gasoline-fueled car, primarily because it could travel longer distances between refueling. In the end, the market rejected electric cars in part because of cost, but more so because of their limited range.

Highway-capable BEVs are not yet in widespread use anywhere in the world, although the Israeli and Danish governments have announced aggressive programs to accelerate their penetration. Gasoline prices in both countries as of January 2011 were above $\$ 7.70$ per gallon, ${ }^{10}$

\footnotetext{
10 “Europe’s Energy Portal.” Accessed at http://www.energy.eu/\#domestic.
} 
and both countries are small and have high population densities. ${ }^{11}$ While several companies produce BEVs in small numbers-for example, BMW, Mitsubishi, Tesla, and Smart-only Nissan Motors has presented a detailed roadmap for selling BEVs to a wide customer base. The Nissan Leaf debuted in the fall of 2010, and the company hopes to sell 5,000 vehicles in the United States in 2011. There are several smaller companies, as well as a couple of larger manufacturers, that are planning to market BEVs by the end of 2012. Most companies, however, are betting that there will be a much stronger market for plug-in hybrids. The trade-off will be between cost and range. BEVs involve fewer parts and thus are predicted to be less expensive, but their reduced range-about 70-100 miles—is considered by some to be a showstopper.

All of the BEVs that will enter mass production in the near-term will follow the traditional model of automobile ownership-the consumer pays the purchase price for the car and is responsible for maintenance and energy costs. Alternative purchasing agreements are possible, such as the consumer buying the car and leasing the battery separately, but these kinds of alternative arrangements do not seem to be a feature of the first generation of mass-produced BEVs.

The second EV option is a plug-in hybrid electric vehicle (PHEV), with batteries that can be recharged by connecting a plug to an electric source, similar to a BEV. Unlike BEVs, when its battery is depleted, a PHEV is capable of running on a small conventional motor. Hence, consumers' range anxiety is substantially reduced. One often sees the acronym "PHEV" followed by the average number of miles that the PHEV can be driven on battery power alone. The U.S. Energy Independence and Security Act of 2007 defined a plug-in electric drive vehicle as a "vehicle that (A) draws motive power from a battery with a capacity of at least four kilowatt-hours; (B) can be recharged from an external source of electricity for motive power, and (C) is a light-, medium-, or heavy-duty motor vehicle or non-road vehicle." ${ }^{12}$

Depending on their design, PHEVs can operate as a series hybrid, a parallel hybrid, or a series-parallel hybrid. In a series hybrid, an internal combustion engine powers a generator, which in turn powers an electric engine (and may send excess energy to a battery), which then powers the vehicle's wheels. A parallel hybrid (for example, most of Honda's current hybrid

\footnotetext{
11 “Our gas costs 25\% more than in Europe.” The Jerusalem Post. January 25, 2011. Accessed at http://www.jpost.com/Business/Globes/Article.aspx?id=205075.

12 "Energy Independence and Security Act of 2007." U.S. Congress. April 1, 2010. Accessed online at http://www.govtrack.us/congress/billtext.xpd?bill=h110-6.
} 
vehicles) can simultaneously power the vehicle's wheels from both the internal combustion engine and an electric drive engine. Series-parallel hybrids (i.e. most of the hybrids offered by Ford, Lexus, Nissan, and Toyota) can operate in either series or parallel mode, depending on driver preference and/or maximum energy efficiency. Most aftermarket PHEV conversions and the Chevrolet Volt are series-parallel hybrids.

While car companies have been experimenting with prototype PHEVs, they have only begun to invest serious money into this option in that past few years. Renault in Europe and BYD in China have already released mass-produced PHEVs to the public. BYD released a PHEV compact sedan in Europe in 2010 and plans to release a similar vehicle in the United States in the fall of 2011. Additionally, Ford, Toyota, and Volkswagen have announced their intentions to begin producing and selling PHEVs by 2012.

Probably the most familiar PHEV is the Chevrolet Volt, which went on sale in the fall of 2010. The Volt is a PHEV-40, which means that it can drive up to an estimated 40 miles on power from the battery alone. After depleting the battery, it can drive an additional 350 miles on gasoline, so range anxiety is much less of a problem. Its efficiency while burning gasoline is 40 MPG, and its initial price after the $\$ 7,500$ tax rebate is $\$ 32,780 .{ }^{13}$ The Chevy Cruze-one of GM's best selling small cars—has many of the same attributes of a Volt, but is priced almost $\$ 14,000$ less.

No one doubts that the auto industry can build electric cars, but the key question is, will consumers buy them? The answer depends on several factors-how does the cost of an electric vehicle compare with a similar model of a conventional car?

If an electric car costs more, what value will the consumer obtain for the extra cost? As noted earlier, a disproportionate percentage of the value of today's electric cars will be in the form of reduced externalities - economic value that the individual consumer has difficulty capturing. Additionally, for many consumers, the lack of range is a significant cost. Technologies are likely to improve over the next decade, and thus the private benefits may increase.

Recharging an EV will require an infrastructure that is readily available (including the recharging equipment and outlets), an upgraded electric distribution grid, and sufficient generation capacity to meet the additional demand. As with so many aspects of the electric car,

\footnotetext{
${ }^{13}$ Cheverlot, “2011 Chevy Volt.” Accessed online at http://www.chevrolet.com/volt/.
} 
the availability of this infrastructure depends on a number of uncertainties. How fast will electric vehicles penetrate the fleet? If slowly, then the market will not want to invest in charging equipment and wire upgrades that are subsequently stranded for many years. Will electric car sales be evenly distributed across the country, or disproportionately located in certain areas, such as the two coasts? Since the conditions of the grid and the adequacy of generating capacity depend on regional variables, one will need to look at this issue at least from a state perspective, if not from that of individual utility franchises. Finally, one has to ask, when will consumers be recharging their vehicles? There is a big difference between scenarios in which a high percentage of consumers charge their vehicles at 7:00 p.m. and ones in which a majority wait until midnight.

We will now look at these three factors, beginning with costs.

\section{Cost Comparison}

We have developed a simple costing model that incorporates a number of assumptions. The model's results are quite sensitive to these assumptions, and there is substantial uncertainty surrounding most of them. Hence, definitive statements on the comparative price of electric vehicles in 2025 do not rest on a robust foundation. We compare the economics of four types of vehicles-conventional internal combustion engine cars (ICEs), conventional hybrids (HEVs), battery-only electric vehicles (BEVs), and plug-in hybrid vehicles (PHEVs), and we consider seven scenarios: 1. approximate cost estimates as they exist in 2010-2011; 2. a conservative estimate of likely (real) costs in 2025-2030; 3. a low battery cost of $\$ 150$ per kWh; 4. a high oil price scenario; 5. a scenario in which the discount factor is $30 \%$; 6. a scenario in which electricity prices rise to $\$ 0.24$ per $\mathrm{kWh}$; and 7. a scenario in which the efficiency of conventional cars reaches 50 MPG and the efficiency of HEVs reaches 75 MPG.

Before looking at the results of our calculations, it is worth examining the three factorsbattery costs, fuel costs, and discount rates-that have the greatest impact on our results.

\section{Batteries}

In EV batteries, power refers to the rate of energy transfer from the battery to the wheels, measured in kilowatts. Greater power equals better acceleration and performance. As a way to compare with an ICE, 100 horsepower is equivalent to 75 kilowatts. ${ }^{14}$ Energy, measured in

\footnotetext{
${ }^{14}$ Electrification Coalition, “Electrification Roadmap,” p. 74. November 2009. Accessed online at http://www.electrificationcoalition.org/sites/default/files/SAF_1213_EC-Roadmap_v12_Online.pdf.
} 
kilowatt-hours (kWh), is a measure of the storage capacity of an EV's battery. Hence, all else being equal, the higher the kWh capacity of a battery pack, the farther a vehicle can be driven between charges. Comparing $\mathrm{kWh}$ of electricity with gasoline, a car with a 15-gallon tank has usable energy capacity equivalent to a BEV with a battery pack of 135 useable $k W h,{ }^{15}$ which would be equivalent to a pack fifteen times that contained in the Chevrolet Volt. ${ }^{16}$

In over a year of interviewing authorities and reading studies, we found no consensus on the cost of batteries in the future, or even the cost today. Estimates ranged from as high as $\$ 875$ per nominal $\mathrm{kWh}^{17}$ to below $\$ 200$ per $\mathrm{kWh}$. In our calculations, we start with an estimate of $\$ 600$ per kWh as today's cost, which is the figure contained in the Electrification Coalition's study. ${ }^{18}$ The coalition consists of electric vehicle advocates, and their estimates are slightly lower than those we have seen in other formal studies, but we believe them to be within the range of reasonableness. If this number is correct, then the $16 \mathrm{kWh}$ battery pack in the Chevy Volt costs approximately $\$ 10,000$, and the Leaf's $24 \mathrm{kWh}$ pack costs $\$ 14,400$, while the Tesla Roadster's $53 \mathrm{kWh}$ pack costs more than $\$ 30,000$. We do not have actual cost data from the companies, but using the numbers published by one of the industry's own coalitions seems like a practical starting point.

The batteries used in today's electric vehicles use lithium and are similar to the batteries that power a laptop computer. The battery costs include 1. obtaining the lithium; 2. building the battery pack to meet rigorous safety and reliability standards, and 3. constructing the plant where the batteries are manufactured. Advocates often forget to include this third element in their estimates - a category that can comprise about $30 \%$ of the total cost of the battery.

Some critics worry about the future availability of lithium. We did not find evidence to support this concern. A typical lithium-ion battery is between three and five percent lithium, ${ }^{19}$ which means that each electric vehicle will need between six and ten kg of lithium per car. The current world reserve of lithium is sufficient to power 1.7 billion vehicles, or about 500 million more vehicles than the total projected to be on the road in 2030. Furthermore, usually 50\% or

\footnotetext{
${ }^{15}$ ICEs have poor efficiency levels relative to electric cars.

${ }^{16}$ We assume that only $65 \%$ of the nominal battery capacity is discharged, similar to the Volt.

${ }^{17}$ Transitions to Alternative Transportation Technologies: Plug-in Hybrid Electric Vehicles (Washington, DC: The National Academies Press, 2010).

${ }^{18}$ Electrification Coalition, “Electrification Roadmap,” p. 79. November 2009. Accessed online at http://www.electrificationcoalition.org/sites/default/files/SAF_1213_EC-Roadmap_v12_Online.pdf.

${ }^{19}$ Fisher, Karen et. al. "Better Waste Management Life Cycle Assessment.” Environmental Resources Management. October 18, 2006. Accessed online at http://www.epbaeurope.net/090607_2006_Oct.pdf.
} 
more of the lithium in a battery can be recycled. Finally, research is being conducted to separate lithium from seawater. Even under a scenario where other uses of lithium increase dramatically, the supply of lithium should be sufficient to meet the needs of an electric vehicle fleet.

Can lithium-ion battery costs be significantly reduced below the estimated $\$ 600$ per kWh figure? The Electrification Coalition has set a goal of $\$ 150$ per kWh. While battery manufacturers keep actual costs a closely guarded secret, at least one has hinted that their costs are already below $\$ 300$ per $\mathrm{kWh}$.

Deutsche Bank has projected that the cost of lithium-ion batteries will decline $7.5 \%$ a year as production increases and will reach $\$ 250$ per $\mathrm{kWh}$ by $2020 .{ }^{20}$ Research on alternative battery types has increased dramatically in the last few years, and there are several promising technologies, including thin-film methods for producing lithium-ion batteries that could dramatically reduce the weight of the battery, as well as lithium-air batteries, which might be able to produce five times the energy per kg of battery mass as current lithium-ion batteries. However, both technologies are at least six years away from penetrating the electric car market.

One of the ongoing difficulties that battery manufacturers must face is enormous pressure to meet safety, reliability, and lifetime performance constraints. A lithium battery is a complex series-parallel electrical machine made of many small voltage batteries. It must be carefully made and managed. A single bad or low resistance cell can cause thermal/electric runaway, damaging or destroying the battery. ${ }^{21}$

Batteries rely on chemical reactions to absorb and discharge electricity; therefore, short circuits and leakage are a concern for the large-scale units used in electric vehicles. Batteries can be damaged by overcharging, exposure to extreme heat or cold, or by impacts and collisions. Manufacturers have to reassure buyers that the batteries in their vehicles will operate under a wide range of weather and driving conditions and that passengers will be safe in the event of an accident. These constraints affect the construction and location of the battery packs, and thus their cost.

In addition, because battery packs are so expensive, manufacturers seek to reassure motorists that they will have a useful and lengthy lifespan. The industry standard seems to be 100,000 miles, which is about ten years. Since battery performance degrades over time as the

\footnotetext{
20 "Deutsche Bank revises li-ion battery cost forecasts downward to $\$ 250 / \mathrm{kWh}$ by 2020,” Green Auto Blog. Accessed online at http://green.autoblog.com/2011/01/06/deutsche-bank-li-ion-battery-cost-forecast-per-kwh/.

${ }^{21}$ Comment received from Robert A. Frosch. March 10, 2011.
} 
battery is discharged and recharged, this constraint has forced manufacturers to make only a portion of the battery available for charging/discharging in order to minimize the stress that comes from deep discharging and recharging and to keep some the battery's capacity as spare reserve. For example, the Chevy Volt only charges its battery to $90 \%$ of its nominal capacity and does not discharge the last $25 \%$ of its nominal capacity. ${ }^{22}$ While this lengthens the useful life of the battery pack, it also greatly increases the cost per useful $\mathrm{kWh}$, and thus the price of the battery. In the case of the Volt, it takes $1.6 \mathrm{kWh}$ of nominal battery capacity to produce $1 \mathrm{kWh}$ of useable energy capacity. The battery industry believes that it can dramatically improve this ratio and will eventually be able to increase useable capacity to more than $90 \%$ of nominal capacity while still meeting safety and reliability standards.

\section{Fuel Costs}

The consumer will only purchase an electric vehicle if he or she perceives that the purchase will provide greater benefits than purchasing a conventional vehicle. One of the strongest private benefits may be the relative lifetime cost of operating an electric vehicle as compared to a conventional passenger car. (We note that this is different from the societal lifecycle cost of the vehicle, but this paper examines the cost from the consumer's perspective because for most consumers, this will be their primary motivation in deciding which vehicle to purchase.) Since battery costs, even under the most optimistic scenarios, will ensure that the upfront capital costs are higher for EVs than conventional vehicles, the only way EVs will be less expensive over their lifetimes is if their operating costs are lower than those for ICEs. Fuel costs dominate the cost of operating a conventional ICE vehicle, and thus gasoline prices are a critical factor in any comparative analysis. If one assumes $\$ 6.55$ per gallon gasoline, the net present cost of purchasing a BEV, even under a $\$ 600$ per $\mathrm{kWh}$ battery scenario, is equal to that of a conventional vehicle, at a $15 \%$ consumer discount rate. (Our costing model is discussed in detail below and presented in full in Appendix A.)

One might argue that gasoline prices might not increase to $\$ 7$ or even $\$ 5$ per gallon. At lower gas prices, electric vehicles are less attractive. We realize that future oil prices are fraught with uncertainty, but in a world where the global vehicle fleet is $60 \%$ larger than today's, we expect that demand will place significant upward pressure on oil prices, and thus a $\$ 5$ per gallon

\footnotetext{
22 "Electrical Energy Consumption in the Chevy Volt." GM Volt company webpage. December 3, 2010. Accessed
} online at http://gm-volt.com/2010/12/03/electrical-energy-consumption-in-the-chevy-volt/. 
scenario seems more likely than a \$3 scenario. The EIA’s Annual Energy Outlook for 2011 projects a 2035 price of $\$ 3.89$ per gallon and a high estimate of $\$ 5.85$ (in 2010 dollars). ${ }^{23}$

A strong possibility remains that between now and 2030 governments will place a value on carbon emissions, either through taxes or policies that will have an equivalent effect. This will push the gasoline price even higher. The bottom line is that the future marketplace for passenger vehicles will probably be characterized by significantly higher oil prices.

One can reasonably argue that electricity prices may also be higher. Nevertheless, even if the price of electricity increases from an average of $\$ 0.12$ per $\mathrm{kWh}$ to $\$ 0.24$ per $\mathrm{kWh}$, its impact on relative vehicle operating costs would be significantly less than a comparable rise in oil prices. For example, increasing the electricity cost in our model of current costs by $100 \%$ (from $\$ 0.12$ to $\$ 0.24$ per $\mathrm{kWh}$ ) increases the net present cost of an EV relative to a conventional gasoline powered vehicle by $\$ 1,606$, but raising gas prices by $100 \%$ (from $\$ 3.75$ to $\$ 7.50$ per gallon) increases the net present cost of a conventional vehicle by $\$ 6,453$. BEV owners may therefore be more insulated from volatile energy prices than owners of conventional vehicles.

\section{Discount Factor}

Electric vehicles will cost more to purchase. However, since they are primarily fueled by electricity, not gasoline, they will have lower operating costs over their lifetimes. To compare operating savings against higher up front capital costs, analysts need to discount the annual operating savings. Hence, the choice of discount rate becomes important in comparing the total lifetime costs of a conventional vehicle to those of an EV.

While one might argue that it is in a consumer's interest to pay more in the form of upfront costs in order to capture the longer-term benefits of reducing operating costs, consumers do not necessarily value the savings in operating costs over the life of a vehicle as highly as theory might lead one to expect. In fact, studies suggest that consumers are reluctant to accept a differential in upfront costs for efficiency gains greater than the difference in fuel costs over the first three years. In other words, they want a payback period that is no longer than three years. Given the volatility in fuel markets, this may be quite rational behavior, but it means that the implicit discount rate used by consumers may be closer to $30 \%-40 \%$ than the $5 \%-10 \%$ one sees in many studies.

23 “2011 Annual Energy Outlook.” U.S. Department of Energy. April 26, 2011. (Washington, D.C., Report \#DOE/EIA 0383 ER 2011). 
David Greene surveyed the economics literature and found that estimates of consumer discount rates varied significantly. He found that many estimates were under $10 \%$, but an equally large number were over $20 \% .{ }^{24}$ Most fell between $4 \%$ and $40 \%$, which is a wide range, but it is not implausible, if one examines discount rates for energy savings from building or appliances. ${ }^{25}$ The choice of discount rate will have a substantial effect on our comparison of the net present costs of the differently fueled vehicles.

\section{Results}

In order to test our assumptions, we constructed a simple model that calculates the net present cost differential between HEVs, PHEVs, BEVs and ICEs. The model and all of the assumptions that go into it are presented in Appendix A.

Our model suffers from a number of limitations. It does not account for financing arrangements such as leases or loans or for battery degradation over time. It assumes a uniform number of miles driven per year and does not account for consumer preferences such as performance, size, and range. Perhaps most importantly, the model does not capture pricing decisions made by the automakers. Nevertheless, we believe it is a helpful tool in illustrating the main drivers of the cost differentials between various vehicle technology types and for demonstrating the sensitivity of cost outcomes to key assumptions and variables.

In our initial case, outlined in Appendix A, we simply wanted to determine the comparative costs in 2011. Unlike all the other cases, this case uses existing numbers and assumptions. We assume a gasoline price of $\$ 3.75$ per gallon (which is approximately equal to pump prices as of mid-June 2011) and battery costs of $\$ 600$ per kWh. We assume that all vehicles in our comparison are driven 12,000 miles per year and that the average price of electricity is $\$ 0.12$ per $\mathrm{kWh}$. We use a discount rate of $15 \%$ and assume there are no government subsidies. Finally, we assume that consumers pay $\$ 1,500$ to install a Level II 220-240 volt outlet to charge their EV and that the plug-in hybrid is driven $85 \%$ of the time in all-electric mode. Some of these assumptions may be optimistic, but all are within the range of reasonableness.

\footnotetext{
${ }^{24}$ Greene, David. "Why the Market For New Passenger Cars Generally Undervalues Fuel Economy.” (Joint Transport Center, OECD) ITE. January 2010. Discussion Paper 2010-6.

${ }^{25}$ Train, K.E., “Discount Rates in Consumers’ Energy-Related Decisions: A Review of the Literature,” Energy, Vol. 10, No. 12 (1985):1243-1253.
} 
We compare the lifetime costs to the consumer of four different vehicles-a conventional ICE vehicle, a conventional hybrid (HEV) using technology similar to that used by Toyota's Prius, a plug-in hybrid with an all-electric range of 40 miles (PHEV-40) and an all-electric vehicle (BEV) with a rated range of 100 miles. The comparison consists of looking at all the costs-both upfront capital costs and operation and maintenance costs-over a ten-year timeframe. To compare the lifetime costs of the four vehicles, we discount the savings in the later years to derive a net present cost for the upfront capital costs and the discounted operation and maintenance costs.

\section{$\underline{\text { Scenario } 1}$}

In the initial case, we find that the net present cost of a conventional car over its lifetime is $\$ 32,861$ (assuming a purchase price of $\$ 21,390$ ); the net present cost of an $\mathrm{HEV}$ is $\$ 33,059$ (assuming a purchase price of \$22,930); the net present cost of a PHEV is $\$ 38,239$ (assuming a purchase price of $\$ 30,235$ ); and the net present cost of a BEV is $\$ 37,680$ (assuming a purchase price of $\$ 33,565)$.

Thus, in 2011 , a conventional car is $\$ 4,819$ less costly over its lifetime than a batterypowered electric car, and is $\$ 5,377$ less than a PHEV-40 (see Table 1 ).

Interestingly, these cost differentials are within a few thousand dollars of the $\$ 7,500$ subsidy now offered by the federal government.

TABLE 1: Today's Costs

\begin{tabular}{|l|l|l|l|l|}
\hline & Conventional & HEV & PHEV & BEV \\
\hline Total Net Present Cost & $\$ 32,861$ & $\$ 33,059$ & $\$ 38,239$ & $\$ 37,680$ \\
\hline Cost Differential with Conventional Car & --- & $\$ 197$ & $\$ 5,377$ & $\$ 4,819$ \\
\hline
\end{tabular}

$\underline{\text { Scenario } 2}$

We then constructed what we believe is a reasonable future base case scenario. We assume that technology breakthroughs reduce battery costs (to $\$ 300$ per $\mathrm{kWh}$ of nominal battery capacity), that gasoline prices increase to $\$ 4.50$ per gallon, and that electricity prices will be $30 \%$ higher (\$0.15 per kWh). Under these assumptions, BEVs are less costly than both conventional ICEs and HEVs. PHEVs remain higher priced than the other three options (see Table 2). 
TABLE 2: Future Costs - Base Case

\begin{tabular}{|l|l|l|l|l|}
\hline & Conventional & HEV & PHEV & BEV \\
\hline Total Net Present Cost & $\$ 34,152$ & $\$ 32,680$ & $\$ 34,601$ & $\$ 30,674$ \\
\hline Cost Differential with Conventional Car & --- & $(\$ 1,472)$ & $\$ 449$ & $(\$ 3,478)$ \\
\hline
\end{tabular}

We used this "future scenario" as the base case for the construction of five additional scenarios, in each of which we varied one of the assumptions.

$\underline{\text { Scenario } 3}$

The assumptions are the same as in Table 2, except that gasoline costs increase to $\$ 6$ per gallon. Electric vehicles, both BEVs and PHEVs, are now less expensive than conventionally fueled vehicles, with BEVs enjoying an advantage of over $\$ 6,000$.

TABLE 3: Future Costs - High Gasoline Prices

\begin{tabular}{|l|l|l|l|l|}
\hline & Conventional & HEV & PHEV & BEV \\
\hline Total Net Present Cost & $\$ 36,733$ & $\$ 34,323$ & $\$ 34,847$ & $\$ 30,674$ \\
\hline Cost Differential with Conventional Car & --- & $(\$ 2,411)$ & $(\$ 1,886)$ & $(\$ 6,059)$ \\
\hline
\end{tabular}

$\underline{\text { Scenario } 4}$

The assumptions are the same as in Table 2, except that the consumer's discount rate is $30 \%$. BEVs are now only slightly less costly that conventional vehicles, illustrating the sensitivity of the cost calculations to the estimates of discount rates.

TABLE 4: Future Costs - High Discount Rate

\begin{tabular}{|l|l|l|l|l|}
\hline & Conventional & HEV & PHEV & BEV \\
\hline Total Net Present Cost & $\$ 29,251$ & $\$ 28,475$ & $\$ 31,349$ & $\$ 28,940$ \\
\hline Cost Differential with Conventional Car & --- & $(\$ 776)$ & $\$ 2,097$ & $(\$ 312)$ \\
\hline
\end{tabular}

\section{$\underline{\text { Scenario } 5}$}

The assumptions are the same as in Table 2, except that battery prices (for both BEVs and PHEVs) are $\$ 150$ per $\mathrm{kWh}$ as opposed to $\$ 300$ per $\mathrm{kWh}$. Electric vehicles' cost advantage is larger than in any other scenario, and BEVs become almost \$6,000 less expensive than plug-in hybrids. 
TABLE 5: Future Costs - Low Battery Costs

\begin{tabular}{|l|l|l|l|l|}
\hline & Conventional & HEV & PHEV & BEV \\
\hline Total Net Present Cost & $\$ 34,152$ & $\$ 32,080$ & $\$ 32,549$ & $\$ 26,971$ \\
\hline Cost Differential with Conventional Car & --- & $(\$ 2,072)$ & $(\$ 1,603)$ & $(\$ 7,181)$ \\
\hline
\end{tabular}

\section{$\underline{\text { Scenario } 6}$}

The assumptions are the same as in Table 2, except that electricity prices are $\$ 0.24$ per $\mathrm{kWh}$ instead of $\$ 0.15$ per kWh. Despite the higher electric price, BEVs are still less costly than other transport options.

TABLE 6: Future Costs - High Electricity Prices

\begin{tabular}{|l|l|l|l|l|}
\hline & Conventional & HEV & PHEV & BEV \\
\hline Total Net Present Cost & $\$ 34,152$ & $\$ 32,680$ & $\$ 35,624$ & $\$ 31,897$ \\
\hline Cost Differential with Conventional Car & --- & $(\$ 1,472)$ & $\$ 1,472$ & $(\$ 2,273)$ \\
\hline
\end{tabular}

\section{$\underline{\text { Scenario } 7}$}

The assumptions are the same as in Table 2, except that the fuel efficiency of conventional cars reaches 50 miles per gallon, while the fuel efficiency of HEVs and PHEVs when burning fuel reaches 75 miles per gallon. Not surprisingly, the price advantages of HEVs and BEVs relative to conventional vehicles decrease, but even in this scenario, BEVs remain the cheapest transport option.

TABLE 7: Future Costs - Higher Fuel Efficiency

\begin{tabular}{|l|l|l|l|l|}
\hline & Conventional & HEV & PHEV & BEV \\
\hline Total Net Present Cost & $\$ 31,829$ & $\$ 31,366$ & $\$ 34,403$ & $\$ 30,674$ \\
\hline Cost Differential with Conventional Car & --- & $(\$ 463)$ & $\$ 2,574$ & $(\$ 1,155)$ \\
\hline
\end{tabular}

In addition to the key variables of gasoline prices, discount rate, and battery pack cost, the costs of BEVs are highly sensitive to desired BEV range (i.e. battery pack size), as greater desired range necessitates a larger battery pack. For example, under the scenario laid out in Table 2 above, increasing the desired BEV range from 100 miles to 150 miles increases the BEV's net present cost by $\$ 3,704$, making it slightly more expensive than a conventionally fueled vehicle. 
Increasing the BEV's range from 100 miles to 250 miles (approximately the range of a new Tesla Roadster) increases the BEV’s net present cost by $\$ 11,111$, making the BEV $\$ 7,633$ more expensive than a conventional ICE.

As a further test of the sensitivity of our model to our key variables, we ran a Monte Carlo simulation, which gave us probability distributions of potential cost differentials, given the distributions for key variables that we input into the simulation. The mean values of the key input variables are the same as the scenario presented in Table 2; the full sensitivity analysis input distributions and results are presented in Appendix B.

The Monte Carlo simulation demonstrates that if one finds the input distributions to be reasonable for the key input variables, there is a strong probability that in the future EVs will, on a net present cost basis, be either cost competitive with or less expensive than HEVs and conventional vehicles. There is also a reasonable probability that PHEVs will be relatively more expensive than either BEVs or HEVs (though again, this model does not take into consideration the economic cost of consumers' potential range anxiety, which we will discuss in the next section).

If, however, one believes that gasoline prices will hover near the $\$ 3.75$ level, that battery technology will not drive costs below $\$ 300$ per $\mathrm{kWh}$, and that consumer discount functions will hover in around 30\% range, the lifetime cost of conventional gasoline vehicles and hybrids will remain lower than that of plug-in hybrids, and in most cases, BEVs.

\section{Comparing Attributes}

There are two schools of thought about how consumers' purchasing behavior will affect the electric car market. The first asserts that consumers look to purchase new vehicles whose attributes are superior to those of their existing vehicles. Few people go to the car dealer looking to purchase a vehicle that has worse performance, fewer accessories, and less room than the car that they are replacing. For electric vehicles to be competitive, they must be able to perform at the same level, possess the same attributes, and be approximately the same size as the conventional cars that they are replacing. For example, the Nissan Leaf is rated up to $90 \mathrm{~kW}$ of power-equivalent to a 120 horsepower in a conventional car-which is in line with a large number of compact and intermediate vehicles, such as a VW Jetta, a Toyota Corolla, or a Ford 
Focus. Thus, if performance were the only point of comparison, the Nissan Leaf is competitive with current ICEs.

However, performance is not the only measure that consumers use to compare vehicles. The two attributes that present the greatest challenge to PHEVs and BEVs are range and reliability. The average conventional vehicle has a range of between 350 and 450 miles per tank of gasoline. Relatively long-range travel in a BEV requires very large batteries. For example, the Tesla Roadster sports car achieves a maximum rated range of 244 miles through a massive 450 $\mathrm{kg}$ (992 pounds) battery pack consisting of 6,831 lithium cells at an estimated cost of $\$ 30,000 .^{26}$ (For a sense of scale, the Toyota Prius HEV has a battery pack of 168 cells that operates at around 36 horsepower.) PHEVs can continue being driven after the electricity in the battery pack is exhausted, which will occur after 20 to 40 miles, depending on the driving conditions and the size of the PHEV's battery pack. Since they are more complicated to build and run at least partially on gasoline, PHEVs will have a higher lifetime cost than comparable BEVs, and this difference may be a good proxy for the range anxiety exhibited by consumers. That is, if consumers pay \$4,000 more for PHEVs than comparable BEVs, that figure may represent the value of eliminating the range anxiety connected with the ownership of a BEV.

The second school of thought argues that range anxiety is overhyped. The proponents of this thesis point out that there are 80 million motorists living in cities or in nearby suburbs. Surveys by the National Highway Administration show that these motorists drive less than 20 miles per day on average..$^{27}$ Thus, on an average day, they would not come close to exhausting the power stored in a BEV with a range of 100 miles. In fact, they would only have to recharge their batteries every two to four days. Furthermore, if charging stations existed at their workplaces or in the parking lots where they shopped, there would be only a few days per year where the range of an electric car would be insufficient. Under these conditions, concern over range might shrink to such a level that consumers would purchase electric cars with smaller batteries at lower prices, improving the comparable cost estimates. In fact, McKinsey released a study asserting that electric cars will make major inroads into the passenger vehicle fleet in large

\footnotetext{
${ }^{26}$ Berdichevsky, Gene et al. “The Tesla Roadster Battery System.” Tesla Motors web archive. August 16, 2006. Accessed online at http://teslamotors.com/display data/TeslaRoadsterBatterySystem.pdf.

${ }^{27} \mathrm{Hu}$ and Reusher. "Summary of Travel Trends: 2001 National Household Travel Survey." Table 5. Page 15.
} 
cities, such as New York, Paris, and Shanghai by 2015, primarily because range will not be an issue for many motorists with daily commutes of less than 30 miles. $^{28}$

If consumers own electric cars, how would they meet their peak demand requirements, such as the 150+-mile trip in the summer to visit family? One solution could be to use the BEV as a second vehicle and purchase a larger conventional vehicle (or PHEV) for longer trips, but for most motorists, this would be an expensive option. Alternatively, the BEV owner could simply rent a larger vehicle with greater range for occasional trips where range and size were important. Assuming rental costs of \$75 per day and \$50 for time lost picking up and dropping off the vehicle, and assuming that such a car was needed 15 days per year (for five trips), then the annual cost would be approximately $\$ 1,375$. The problem is that if the number of peak demand trips posited above exceeds one per month (under our future baseline scenario), the net present cost advantage may shift back to favor conventional gasoline-powered vehicles over BEVs. Hence, the range limitations of BEVs may deter a family with even a moderate number of peak demand days.

The central problem with this second line of argument is that it requires consumers to change their buying habits dramatically. Consumers are more likely to purchase a car that meets their needs $100 \%$ of the time as opposed to $90 \%$ of the time. Hence, purchasing vehicles with limited range will require a significant change from the status quo. One might argue that a status quo that induces consumers to purchase relatively inefficient, two-ton vehicles to drive less than twenty miles per day in order to have the vehicle available for ten, five, or even fewer trips per year of 150+ miles may not be an economically optimal scenario. Perhaps this is true, but it would be hard to deny that this consumer behavior exists. For EVs to gain significant fleet penetration, manufacturers of EVs will require strategies for overcoming this buying pattern.

The reality that the actual range of a BEV may be less than the maximum rated range per charge exacerbates this problem. For example, actual mileage of a Nissan Leaf may be significantly less than 100 miles per charge. If the driver uses the air conditioner, entertainment equipment, or even headlights, electricity will be drawn from the battery, leaving less available for driving the vehicle. Even if the actual mileage available were closer to 60 miles per charge, most commuters would not be inconvenienced, because average daily mileage is below 20 miles

\footnotetext{
${ }^{28}$ Hensley, Russell et al. “The Fast Lane to Adoption of Electric Cars.” McKinsey Quarterly. February 2011.
} 
per day. Nevertheless, most automobile buyers are risk-averse, and 60 miles per charge triggers more range anxiety than 100 miles.

Some might point out that if electric car owners only average 20 miles per day, they would be likely to drive 6,000 miles or less per year. Therefore, the numbers in our earlier calculations might misstate the net present cost advantage of EVs. It is true that an electric car that is driven 6,000 miles per year will use less electricity than one that is driven 12,000 miles. However, electricity is not very expensive, so the additional net present savings of cutting one's driving in half in a BEV would be about $\$ 1,000$ under our future baseline scenario. By contrast, if the owner of a conventionally fueled car drives it 6,000 miles per year instead of 12,000, the net present cost of his vehicle would decrease by just over $\$ 4,000$. Thus, conventional cars would benefit more than electric vehicles if they are driven less, since the marginal cost of driving a conventional car (the price of gasoline) is far greater than the marginal cost of driving a $\mathrm{BEV}$ (the price of an equivalent amount of electricity). Therefore, the more a car is driven, the greater the lifetime cost advantage of BEVs over ICEs.

While range anxiety may be the greatest challenge, it is not the only attribute that concerns potential BEV purchasers. BEVs and PHEVs are unfamiliar technologies to the average consumer, who has been driving some version of gasoline-powered car his or her entire life. Since a new vehicle is usually the most expensive purchase (other than a new home) that consumers make, they are usually risk-averse when purchasing vehicles. Consequently, they will likely purchase vehicles that closely resemble the ones they currently own. In addition, brand loyalty runs deep-even when cars are actually quite similar. In this case, we are talking about technology loyalty, which may run even deeper than brand loyalty.

Admittedly, very little data exists on the reliability of electric vehicles, and for this reason, we emphasize consumer perceptions as opposed to factual realities. The industry is aware of this problem and has invested billions of dollars to ensure that EVs operate as reliably as conventional vehicles. However, it will take time for the public to adjust its perceptions. To accelerate this process, the government offers tax credits to early adopters who are willing to take on the perceived technology risks. These credits expire either over time (as in Europe) or after a certain number of cars are sold (as in the United States).

What other attributes might attract consumers to EVs? Some people cite the opportunity to sell backup power to the grid with vehicle-to-grid (V2G) technologies, which under some 
scenarios may reduce the cost of power to almost zero while dramatically improving the efficiency of the grid. If smart grids emerge, and EVs are all hooked up to those grids, and if consumers are assured that the effective operation of their vehicles will not be compromised, the ability to arbitrage electricity prices in order to offset the costs of EV ownership might be valued. However, at the moment, such an application remains in the realm of a speculative benefit as opposed to an actual one.

Some argue that recharging a car at home will prove to be more convenient than having to drive to the local gasoline station to fill up. Again, this may be the case, but is it worth paying an additional $\$ 50, \$ 250, \$ 1,000$, or $\$ 4,500+$ ? There is no actual data with which to answer this question, but we suspect that most consumers will not be willing to pay much to avoid weekly trips to the gas station. Further, the possibility exists that PHEV owners will simply "forget" or stop charging their vehicle regularly and instead run it on gasoline most of the time.

Other benefits asserted by EV advocates include reduced pollution, greater vehicle efficiency, improved national energy security, and reduced carbon emissions. All of these benefits are real and may prove to be large, but they are all public benefits (or positive externalities), which are not captured by the private individual. Admittedly, there will be individuals who place a large value of being more environmentally responsible, and they are likely to be less dissuaded by high initial prices or limited range than the majority of consumers. ${ }^{29}$ However, as stated earlier, these consumers account for a small segment of the population.

The bottom line is that electric vehicles currently do not provide private attributes and benefits that exceed, or even equal those of most conventional gasoline-powered cars. Range deficiency is the single largest technical barrier separating electric vehicles from their gasoline counterparts, compounded by long recharge times when compared to filling up at a gas station. As we have discussed, the cost of range anxiety depends on the individual. The most obvious measure would be the net present cost difference between a PHEV and a comparable BEV, which in our scenarios ranges from about $\$ 2,500$ to $\$ 5,500$. As mentioned earlier, there may be other measures. As more EVs show up in company showrooms, we will begin developing a database from which analysts can answer this question. Moreover, research on producing lighter

\footnotetext{
${ }^{29}$ Gallagher, Kelly Sims and Erich Muehlegger. "Giving Green to Get Green: Incentives and Consumer Adoption of Hybrid Vehicle Technology." Working Paper, John F. Kennedy School of Government,_Harvard University, February 2008.
} 
and more efficient batteries continues, and a new technology may emerge that will dramatically increase the range of electric vehicles at a fraction of today's battery cost. But until this occurs, range anxiety will remain a major concern of most consumers.

\section{Adequacy of Infrastructure}

Electric cars are fueled wholly or partly by electricity, which presumes access to a reliable source of power. Equipment for connecting an EV to a source of electricity is required, at home and/or outside the home. Proponents are concerned that adequate electric distribution and transmission infrastructure might not exist when and where it is needed. This concern goes to the heart of the debate in Congress over the question of whether to subsidize installation of public charging stations in five to fifteen EV deployment communities. ${ }^{30}$ Our initial conclusion is that a market failure justifying a strong federal presence is not evident. While there are regional differences in the adequacy of the existing electric distribution, transmission, and generating systems, there is no evidence to conclude that investments will not be forthcoming from private companies to meet those needs, if and when they manifest themselves.

Historically, early purchasers of gasoline-powered cars faced a similar dilemma. There were no gasoline stations during the first decades of the automobile era. Owners bought gasoline from grocery stores and pharmacies. Even when demand for gasoline was in its infancy, some storeowners in the community saw an opportunity to make some money and added gasoline to their supply inventory. As the demand grew, so did the number of individuals or companies that sold gasoline, until dedicated retail establishments emerged as the forerunners of the modern gasoline station.

To an extent, providing electricity for vehicles will be an easier task, since every household has access to power, which was not the case with gasoline. Nevertheless, it is worth examining the possible future electricity capacity needs and assessing the ability and willingness of the private sector to meet them.

We anticipate that most EV owners will want to charge their vehicles at home, so appropriate charging infrastructure is needed at each household. A standard wall outlet will provide power at 110 volts and 20 amps. In the simplest case, owners can run an electric cord

\footnotetext{
${ }^{30}$ The Electric Vehicle Deployment Act of 2010, U.S. Congress (S.3442, H.R. 4442). Accessed online at http://www.govtrack.us/congress/bill.xpd?bill=s111-3442.
} 
from the house to the EV. The electric load will be equivalent to adding a new clothes dryer to the house, which means that an electrician will likely be needed to install a dedicated outlet, though many houses would be able to manage the extra electricity pull without any additional wiring. This type of connection is labeled a Level I system and is relatively inexpensive, assuming that the vehicle comes with the equipment to receive the electric charge. The downside is that the charging process is excruciatingly slow. For example, charging a Tesla Roadster from "empty" on a Level I system will take over thirty hours, and fully charging a Nissan Leaf from "empty" will take about twenty hours. Charging the Chevy Volt (a PHEV) from "empty" will take about seven hours, so if the owner plugged in her Volt at 10:00 p.m., it would be ready by early morning.

In practice, most EV owners will find Level I charging unacceptable as a sole energy source and will install a Level II charging system, which operates at 220 volts and between thirty and forty amps. With this system, a Nissan Leaf could be charged in seven hours. ${ }^{31}$ Such a system would equal the electric pull of about two clothes dryers, and thus installing such a system would be approximately the same as adding one-half a house to a normal residential area. A Level II system can be installed by any licensed electrician and includes a special connector. The cost estimates vary and are likely to decrease over time, but are now approximately $\$ 1,500$ $\$ 2,200$ per household. ${ }^{32}$

A popular topic among EV enthusiasts is "quick charging," which is charging an electric car in approximately the same time it takes to fill up a gasoline car at your local gasoline station. These Level III systems draw about 210 kilowatts for ten minutes, or about the same draw as 140 houses, if one assumes that each home draws about $1.5 \mathrm{~kW}$ of power. The current could be up to 500 volts at 200 amperes, which would require very expensive conductors and sophisticated safety systems. This system has been demonstrated and is technically feasible, but for safety reasons, would only be available at dedicated service stations. Finally, Level III charging would likely subject the battery pack to significantly greater wear and tear than Level II charging and may cause the EV battery to degrade more quickly.

\footnotetext{
31 "Nissan Leaf: Charging FAQ.” Nissan USA company website. Accessed online at http://www.nissanusa.com/leafelectric-car/faq/list/charging\#/leaf-electric-car/faq/list/charging.

${ }^{32}$ Bristow, Nick. “2011 Leaf US Pricing Officially Announced.” Autoblog Green website. Accessed online at http://green.autoblog.com/2010/03/30/2011-nissan-leaf-us-pricing-officially-announced-as-low-as-25/.
} 
Level III charging would also put an enormous strain on the existing electric distribution systems and would require an industrial-sized substation to handle the power surges at each individual location. The cost of this system would be substantial, though we were not able to identify estimates that we could confidently embrace.

If EVs gain popularity, there will be pressure to install these systems at commercial locations. Consumers would either pay a monthly fee to access the public chargers or pay per use, similar to how a transponder works on a toll road. The cost for commercial Level II chargers would be slightly less than household installations, since they could be installed in arrays of four to six connectors at a time. Coulomb Technologies advertises pole-mounted stand-alone Level II charging systems for $\$ 2,000$ to $\$ 6,000,{ }^{33}$ but we suspect that the actual prices will usually be less and fall over time as competition among manufacturers of Level II chargers increases with demand. Given the low upfront costs and the existing menu of payment options, private providers, in partnership with utilities or as stand-alone enterprises, will be prepared to make these investments. Furthermore, there are no major barriers to entry. Thus, if the demand materializes, a competitive industry should also develop to meet it.

If one is skeptical and believes that governments must intervene and subsidize the upfront costs of non-residential charging stations, a demonstrated market failure must justify government involvement. Will the local utilities fail to make the investments, and will they prevent others from investing? The former scenario is quite possible, given that utilities are riskaverse investors, but there is no reason that they would not welcome new paying customers, especially if they themselves do not have to take any of the front-end risk. Given that charging stations are relatively inexpensive and can be erected in a matter of hours, the system can expand to meet demand quite easily.

The principal argument for government intervention is timing. Though the private sector will invest in charging stations, it probably will not do so until sufficient demand generates a revenue stream to earn a reasonable rate of return on its investment. Thus, governments are being asked to invest in advance of demand and take at least some of the losses in the early years before the EV population is sufficient to make such a public charging system profitable. This scenario is not a market failure; it is the granting of a subsidy to induce consumers to buy electric

\footnotetext{
33 “Coloumb Charging Stations.” Coulomb Technologies. July 15, 2010. Accessed online at
} http://www.coulombtech.com/products-charging-stations.php. 
cars and has little to do with infrastructure needs. Furthermore, it could potentially distort the system and erode the incentives for private entrepreneurs to get into the recharging market. It is akin to offering subsidized gasoline for anyone buying a particular make of car and having the government subsidize the gasoline.

Finally, proponents argue that urban residents are more likely to buy electric cars than those living in rural or suburban neighborhoods, but many urban dwellers do not have private garages and therefore park on the street. Lack of on-street charging will be a major deterrent to owning an electric car in dense city environments. While installing on-street charging will make a difference, it will be more cost-effective for cities to enter into partnerships with private companies to install and maintain the equipment in return for a fee or lease payment. There will be cases, however, of consumers who may delay the purchase of EVs due to lack of on-street charging equipment. If the number is large or even moderate, fewer electric cars will be sold, but as some stage, private entrepreneurs will see an opportunity to make money and push the city government to allow them to install changing stations. Furthermore, it is not obvious that onstreet charging will be embraced. Legal concerns, liability issues, and the threat of vandalism may make on-street charging unappealing. Placing charging stations in garages, parking lots, and even special stations may be a more acceptable alternative.

While the argument favoring government subsidies for the installation of public charging stations is not supported by evidence of any market failure, strong government regulation to set standards for such charging equipment is needed. Europe is beginning to establish standards for privately sold charging equipment to ensure that they are compatible with new EVs and meet strict safety regulations.

Projections of possible impacts of EVs on the grid vary greatly according to location, time of day, and the technology used for charging. Kintner-Meyer et al. and Denholm and Short examine the potential impact of PHEV adoption on the U.S. grid (the impact of which would be, by definition, smaller than an equivalent number of BEVs) and conclude that if the PHEVs were charged at lower voltages at optimal times of day (i.e. night), then between $50 \%$ and $73 \%$ of the U.S. light duty vehicles could be converted to PHEVs and be supported by the existing electric 
infrastructure. ${ }^{34}$ These numbers assume that the grid can remain relatively stable while constantly running at or near $100 \%$ capacity, which may not be realistic, but their analyses suggest that a substantial number of EVs could be absorbed by the current grid without adding generating capacity.

Local percentages will vary by region. Current capacity in the eastern U.S. should be able to support a higher percentage of EVs in the vehicle pool than current capacity in western states. Within these regions, there will be utilities that are capacity short and others that will be capacity long, and thus national averages do not have much significance when examining the situation in a particular state or county. As technologies change and the level of fleet penetration increases, more investment will be needed. This is especially true if consumers gravitate towards BEVs as compared with PHEVs. Furthermore, these projections assume that EV charging equipment will be able to communicate to the grid in order to synchronize the supply and demand in such a way that the system is optimized. In other words, these studies assume that utilities will have already invested in smart grid technology, which may or may not be the case.

In the same way that generation capacity to supply electric vehicles varies by region, so too does the need to enhance the distribution systems. In some localities, there will be a need for significant new investment. For example, if every home in a ten-house cul-de-sac installed a Level II charging system, the pull on the transformers would be equivalent to adding approximately five new homes. Hence, the utility would probably have to upgrade its distribution system. On the other hand, there will be areas where the addition of some electric cars will not make much of a difference and will not require much investment.

In a very optimistic scenario, let us assume that $30 \%$ of the vehicles in Southern California shift to electric cars by 2030. This would be over two million vehicles. Let us further assume that all of their owners install a Level II system at their homes and that an additional 300,000 charging stations are installed in commercial locations. If the ratio of households to cars is 1.25 to 1 , then the draw on the distribution system would be equivalent to about four million new clothes dryers - a substantial increase in demand. However, the utility would have twenty years to make the necessary investments, assuming linear growth in electric vehicles and no

\footnotetext{
${ }^{34}$ Kintner-Meyer, M. et al. "Impacts Assessment of Plug-in Hybrid Vehicles on Electric Utilities and Regional U.S. Power Grids.” November 2007. Accessed online at https://www.ferc.gov/about/com-mem/wellinghoff/5-24-07technical-analy-wellinghoff.pdf; and P. Denholm and W. Short, "An Evaluation of Utility System Impacts and Benefits of Optimally Dispatched Plug-In Hybrid Electric Vehicles.” October 2006. Accessed online at http://www.nrel.gov/docs/fy07osti/40293.pdf.
} 
major change in battery technology. Thus, the utility would only have to upgrade a small percentage of its system every year. The actual percentage and cost would be specific for each utility.

The larger question is who will pay for these upgrades? In many parts of the country, the unbundling of the electric utility industry separated transmission and distribution from generation and focused attention on issues such as transmission tariffs and access-issues that had been bundled with the costs of generation in the old vertical integrated model. Over the last ten years, some states have found their transmission systems congested and in need of additional investment. Since these systems are part of a larger grid, the logical assumption was that all of the consumers in the area serviced by the grid would pay for the needed upgrades. This policy did not sit well with states or regions that possessed adequate transmission capacity. They did not want their consumers to pay for investments in other states-investments that would only benefit "other" users. These concerns gave rise to policies embraced by state and federal regulators that new transmission investments should be paid for by the beneficiaries of the investments. Implementing such a policy, however, is challenging. Who are the beneficiaries? Does their identity change over time? How much do they benefit?

These questions are at the forefront of the current regulation policy debate, and public utility commissions are working to address them. Initially, this debate focused on transmission upgrades, but there is no reason that it cannot apply to distribution systems as well. This issue is less of a problem for generators, since in more than half the country, generators are independent power producers, and whoever buys the power pays.

How does this issue affect electric cars and the rate of investment in charging equipment? In the initial stages of the industry, it will not, since the number of electric vehicles sold will be small. However, if President Obama's goal of one million electric vehicles by 2015 were to materialize, EV sales would constitute about $7 \%$ of car sales. Such sales would probably not be evenly distributed across the country. For example, the percentage in California and the northeast might be larger-for example, $15 \%$ of new car sales rather than $7 \%$.

At this stage, local utilities in these areas could be under pressure to invest significant capital in upgrading their distribution systems in order to accommodate the new load. If much of the incremental demand is driven by the installation of charging equipment for electric cars, EV owners will benefit directly from these investments. Who should pay? This issue is complicated 
by the fact that utilities might want to upgrade their systems in advance of this demand. How does a utility identify a potential electric vehicle owner? Is it fair to bill someone for an investment that he or she might use five years hence?

The easiest solution would be to have everyone on the grid pay for the improvements, but it is likely that a portion of the stakeholders will insist on compliance with the "beneficiary pays" principle. This problem is solvable, but will create a policy challenge and may slow investment in upgrading the distribution and transmission systems.

Finally, if the need for additional power emerges rapidly and existing siting and permitting hurdles for new power plants remain, utilities will be under pressure to keep their older plants in use, since they will not be able to permit, finance, and build new facilities fast enough. In many parts of the country, these plants are coal-fired. The irony is that a rapid electrification campaign, justified on environmental and climate grounds, may extend the life of many older and dirtier coal plants, significantly diluting the environmental benefits of electric vehicle adoption.

If the argument in favor of government intervention to ensure that charging stations are available is not compelling, why is it being made and, in many cases, accepted? There are two possibilities. In the first case, one might argue that our confidence that private parties will respond to an emerging demand for public charging stations is misplaced and that they will instead ignore this market opportunity. For the reasons stated above, we do not find this argument compelling. In the second case, perhaps the demand for EVs will not emerge unless public charging stations are widely available. People will purchase fewer electric vehicles than they otherwise would due to worries about the absence of charging opportunities beyond their homes. Since one charge per night will provide about 50-70 miles per day and most people living in urban areas drive less than twenty miles, this issue may be more of a perception problem than a real one, especially if most people opt to buy PHEVs as opposed to BEVs. But even if it is primarily a problem of perception, it will still almost certainly retard some investments in electric vehicles.

Thus, government subsidization of public charging is aimed at spurring consumers at the margin to purchase new electric cars. A logical question would be, if the government wants to provide an additional subsidy to spur EV sales, is subsidizing the installation of public charging stations the best way to do so? Perhaps increasing tax credits to consumers from $\$ 7,500$ per 
vehicle to $\$ 10,000$ or extending the life of the credit beyond the first 250,000 vehicles produced would be more effective and more economical.

\section{Conclusion}

The recent history of U.S. energy policy is replete with examples of generous support for new technologies. Starting with nuclear power in the 1960s and 1970s, to synthetic fuels in the late 1970s and early 1980s, and more recently to biofuels, Americans have enthusiastically embraced the promise of new energy technologies, only to become disappointed when expectations were not met. It takes longer than one anticipates to develop and commercialize new energy technologies, and public support for policies, as well as technologies, can be shortlived and fickle. Nuclear power, for example, plays an important role in the country's energy mix, but plays a much smaller role than its supporters predicted forty years ago. Biofuels may play a significant role in the future, and synfuels are getting a new look as countries like China search for alternative uses for their coal reserves. But whatever benefits they provide will almost certainly emerge more slowly than originally predicted.

The challenge is that millions of people and/or organizations have to buy these new technologies. When the country invested millions of dollars to put the first man on the moon, there was one buyer - the U.S. government — and price was not an issue. In the case of energy, producers have to sell their technologies and, more importantly, the services provided by those technologies to millions of consumers.

If electric vehicles are to penetrate the market sufficiently to have a measurable impact on gasoline consumption (and oil imports) or to be able to reduce carbon dioxide emissions significantly, then millions of consumers will have to purchase those vehicles. Seven thousand consumers bought electric cars in 2009, and this number will easily increase to over 50,000 vehicles per year in the next few years. The test, however, is whether electric vehicles can surpass 2.5 million vehicles sold per year, which would allow the industry to capture $20 \%$ of the U.S. new car market by 2025. To put this goal in perspective, sales of conventional hybrids (HEVs) in 2009 in the United States remained below 300,000 vehicles. ${ }^{35}$ Reaching sales levels above $2.5 \%$ of the new car market means convincing consumers that an electric car provides

\footnotetext{
35 “J.D. Power: Annual U.S. Hybrid Sales Beyond 1 million by 2015,” HybridCars.com. Accessed online at http://www.hybridcars.com/news/jd-power-annual-us-hybrid-sales-beyond-1-million-2015-28126.html.
} 
benefits that in aggregate are equal to (or greater than) those of an equivalent conventional gasoline-powered car.

Our study shows that in a scenario characterized by increases in gasoline prices and decreases in battery costs approximately in line with what the industry is predicting, batterypowered electric cars will cost less than conventional gasoline-powered vehicles over the course of their lifetimes. This result is absent the existing $\$ 7,500$ tax credit or any other federal subsidy. If gasoline prices turn out to be even higher, either because of future demand/supply imbalances or because of additional taxes on gasoline or carbon, electric cars, particularly BEVs, will have a significant net present cost advantage. We find that if the only issue were cost, government subsidies may not be needed past 2015. If oil prices decrease instead of increase, this will not be the case, but we believe that oil prices in 2015 will probably be measurably higher than those in 2010.

The only case where this scenario does not hold is if one assumes that consumers have a very high discount rate in calculating the value of the gasoline costs avoided over the life of the electric car. Thus, the lifetime cost advantages that EV proponents extol may not be embraced by consumers who do not value savings beyond those that pay back in three years. Furthermore, some consumers do not retain their cars beyond three to five years, and thus lifetime cost benefits measured over ten years are not very meaningful to them. For these consumers, the trade-in value of EVs will be a key aspect of their decision-making process, and little data on EV trade-in values currently exists.

If the reader embraces the high discount rate scenario, then to sway large numbers of consumers to purchase them, either EVs will have to have a clear upfront ("sticker") cost advantage over conventional cars, or gasoline prices will have to be closer to $\$ 6-\$ 8$ per gallon than $\$ 4$.

Perhaps the biggest challenge facing electric cars is providing attributes-particularly range - that are equal to or superior to those of conventional vehicles. Consumers want to purchase new cars that provide comparable or superior attributes to their current (ICE) vehicles. Electric car manufacturers have worked very hard to achieve comparability in every area, save range. To eliminate this constraint completely, the industry must find new battery technologies that are lighter and less expensive and that can withstand harsh driving conditions; or the industry must make breakthroughs in lithium-ion technologies that most battery experts believe 
is improbable. The former may happen, but if it does, the new technologies are unlikely to be commercialized before 2018.

Alternatively, many urban-dwelling car buyers may discover that their range anxiety is irrational. While consumers in Nebraska and South Dakota will not rush to their local electric car dealer, those in New York, Washington, D.C., San Francisco, Baltimore, and Chicago may find that electric cars fit their needs well. This scenario may be even more realistic in Chinese and Indian cities than in the United States. The problem is that it is very difficult to change consumer habits and preferences. The consumer who drives 20 miles or fewer 340 days per year buys a vehicle not for 340 days, but for the 25 days that their family drives $100+$ miles. Since these trips are often in the summer to more rural locations, the existence of charging stations at their work places or at their shopping mall parking lots may not resolve the problem.

A scenario like the one painted by the recent McKinsey report (in which urban dwellers aggressively purchase electric vehicles) is possible, but in our view, is unlikely, unless either gasoline prices are in the $\$ 5+$ per gallon range and battery costs fall considerably, or the government aggressively restricts certain urban areas to electric cars only. A number of European cities already have travel restrictions in place, such as pedestrian-only downtown areas, or very high congestion or cordon pricing schemes, such as in London and Stockholm. It is not outside the realm of plausibility to see similar restrictions that favor electric vehicles, but again, they are much more likely to occur in Europe, China, and/or India than in the United States.

In summary, significant penetration of electric cars into the U.S. marketplace will only occur if the vehicles are competitive with conventional vehicles, not only on a cost basis, but also on an attribute basis. We believe that for this to occur, 1 . gasoline prices will have to increase to or beyond $\$ 5$ per gallon; 2. the government will have to accelerate such an increase by placing a price on those externalities - pollution, imported oil, or greenhouse gases-that it wishes to reduce, and 3. the industry must develop a battery technology that will permit electric cars to travel greater distances at lower costs, probably with aggressive government support in the research, development, and deployment of these new technologies.

A future in which electric cars play a significant role in the nation's transportation system is not a pipe dream, but it will not happen without higher gasoline prices and a much stronger partnership between private industry, the federal government, and state and local governments. 


\section{Appendix A: Cost Model at Current Energy Prices}

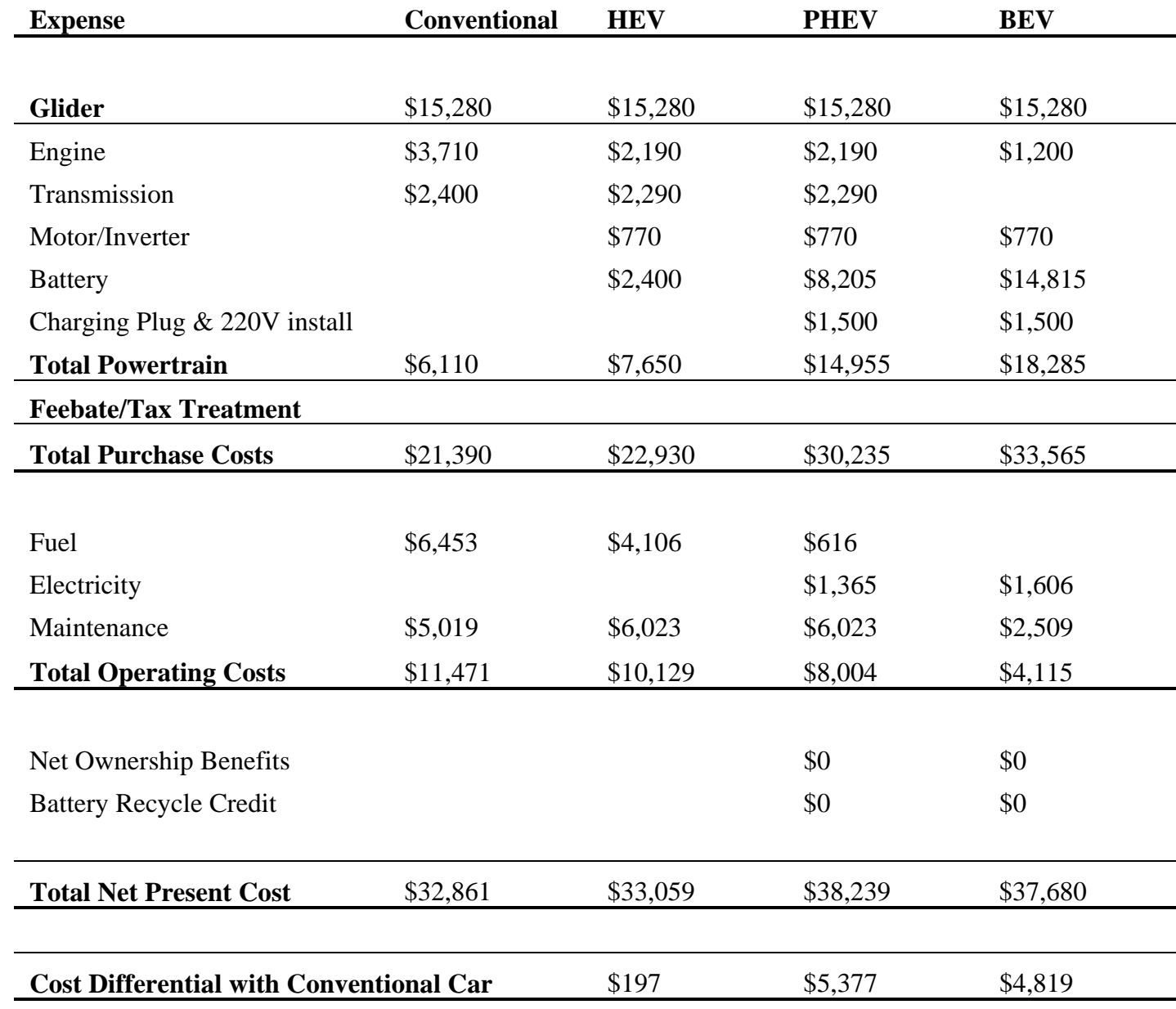

V2G Benefit (\$ per kWh usable capacity per year):

Miles Driven Per Year:

Useful Life Years:

Price of Electricity $(\$ / \mathrm{kWh})$ :

Miles per kWh (of nominal battery capacity):

Desired PHEV all-electric range (Miles):

Useable battery capacity, PHEV:

Desired BEV Range (Miles):

Conventional Maintenance Costs per Year: 


\section{Appendix B: Monte Carlo Simulation and Sensitivity Analysis}

Simulation Inputs:

\section{EV Scenario Analysis - I nputs}

\begin{tabular}{|c|c|c|c|c|c|c|c|}
\hline Name & Graph & Min & Mean & Max & $5 \%$ & $95 \%$ & Distribution Type \\
\hline Fuel Price per Gallon: & 2.0 & $\$ 2.50$ & $\$ 4.50$ & $\$ 6.50$ & $\$ 2.70$ & $\$ 6.30$ & Uniform \\
\hline $\begin{array}{l}\text { Battery Pack Cost ( } \$ / \text { kWh), } \\
\text { PHEV: }\end{array}$ & ${ }^{100}$ & $\$ 150$ & $\$ 300$ & $\$ 450$ & $\$ 191$ & $\$ 409$ & Beta \\
\hline Discount Rate: & & $5 \%$ & $15 \%$ & $25 \%$ & $6 \%$ & $24 \%$ & Uniform \\
\hline Avg. Conventional MPG: & & 30.29567 & 34.99993 & 77.61208 & 31.72219 & 40.67329 & Log Normal \\
\hline Miles Driven Per Year: & & 9,049 & 12,000 & 23,398 & 10,364 & 14,209 & Log Normal \\
\hline $\begin{array}{l}\text { Battery Pack Cost (\$/kWh), } \\
\text { EV: }\end{array}$ & $\nabla$ & $\$ 150$ & $\$ 300$ & $\$ 449$ & $\$ 191$ & $\$ 409$ & Beta \\
\hline Level II Charging Plug Cost: & & $\$ 859$ & $\$ 1,500$ & $\$ 2,187$ & $\$ 1,253$ & $\$ 1,747$ & Normal \\
\hline $\begin{array}{l}\text { Conventional Maintenance } \\
\text { Costs per Year: }\end{array}$ & $\nabla$ & $\$ 527$ & $\$ 1,000$ & $\$ 1,437$ & $\$ 836$ & $\$ 1,164$ & Normal \\
\hline $\begin{array}{l}\text { HEV Maintenance Costs per } \\
\text { Year: }\end{array}$ & 600 & $\$ 664$ & $\$ 1,200$ & $\$ 1,733$ & $\$ 1,003$ & $\$ 1,397$ & Normal \\
\hline $\begin{array}{l}\text { PHEV Maintenance Costs per } \\
\text { Year: }\end{array}$ & $\mathbf{7}$ & $\$ 561$ & $\$ 1,200$ & $\$ 1,712$ & $\$ 1,003$ & $\$ 1,397$ & Normal \\
\hline $\begin{array}{l}\text { EV Maintenance Costs per } \\
\text { Year: }\end{array}$ & 250 & $\$ 277$ & $\$ 500$ & $\$ 722$ & $\$ 418$ & $\$ 582$ & Normal \\
\hline $\begin{array}{l}\text { Avg. HEV/PHEV MPG using } \\
\text { only fuel: }\end{array}$ & 年 & 50.38216 & 54.99996 & 98.15335 & 51.72213 & 60.67326 & Log Normal \\
\hline $\begin{array}{l}\text { Percent of PHEV miles driven } \\
\text { in electric-only mode: }\end{array}$ & $\nabla^{0.70}$ & $75 \%$ & $85 \%$ & $95 \%$ & $76 \%$ & $94 \%$ & Uniform \\
\hline Electricity Price/kWh: & $\mathbf{v}^{0,0}$ & $\$ 0.10$ & $\$ 0.15$ & $\$ 1.28$ & $\$ 0.11$ & $\$ 0.23$ & Log Normal \\
\hline
\end{tabular}


Notes: The simulation was run with 100,000 iterations. In this Appendix, "EV" refers to "BEV" as defined in the text. If a model variable does not appear in the above table, it was fixed at the value given in Appendix A.

Simulation Output Summary:

\begin{tabular}{|c|c|c|c|c|c|c|}
\hline \multicolumn{7}{|c|}{ EV Scenario Analysis - Outputs } \\
\hline Name & Graph & Min & Mean & $\operatorname{Max}$ & $5 \%$ & $95 \%$ \\
\hline $\begin{array}{l}\text { Cost Differential with } \\
\text { Conventional Car / HEV }\end{array}$ & Vk & $(\$ 10,597)$ & $(\$ 1,582)$ & $\$ 4,532$ & $(\$ 4,199)$ & $\$ 582$ \\
\hline $\begin{array}{l}\text { Cost Differential with } \\
\text { Conventional Car / PHEV }\end{array}$ & ${ }^{20 k}$ & $(\$ 13,498)$ & $\$ 972$ & $\$ 17,823$ & $(\$ 4,014)$ & $\$ 5,110$ \\
\hline $\begin{array}{l}\text { Cost Differential with } \\
\text { Conventional Car / EV }\end{array}$ & 20k & $(\$ 21,777)$ & $(\$ 3,863)$ & $\$ 17,102$ & $(\$ 10,310)$ & $\$ 1,445$ \\
\hline
\end{tabular}

Note: The simulation was run with 100,000 iterations. In this Appendix, "EV" refers to "BEV" as defined in the text. 


\section{Simulation Output for Cost Differential with Conventional Car / EV}
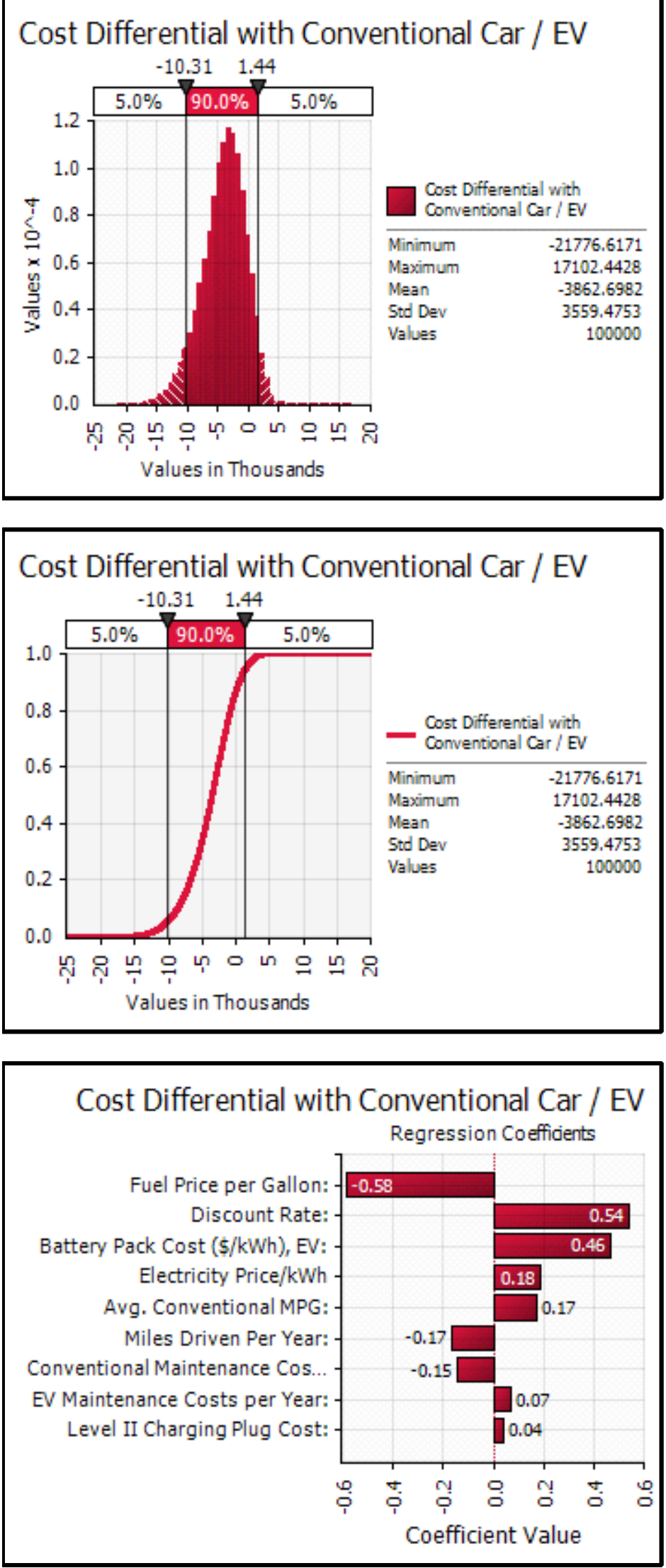

\begin{tabular}{|l|l|}
\hline Simulation Summary Information \\
\hline Number of Simulations & 1 \\
Number of Iterations & 100000 \\
Number of Inputs & 14 \\
Number of Outputs & 3 \\
Sampling Type & Latin Hypercube \\
Random \# Generator & Mersenne Twister \\
Random Seed & 1981150932 \\
& \\
\hline
\end{tabular}

\begin{tabular}{|l|l|r|l|}
\hline \multicolumn{3}{|l|}{ Summary Statistics for EV Cost Differential } \\
\hline Statistics & \multicolumn{1}{|l|}{ Percentile } \\
\hline Minimum & $(\$ 21,777)$ & $\mathbf{5 \%}$ & $(\$ 10,310)$ \\
Maximum & $\$ 17,102$ & $\mathbf{1 0 \%}$ & $(\$ 8,675)$ \\
Mean & $(\$ 3,863)$ & $\mathbf{1 5 \%}$ & $(\$ 7,604)$ \\
Std Dev & $\$ 3,559$ & $\mathbf{2 0 \%}$ & $(\$ 6,772)$ \\
Variance & 12669864.68 & $\mathbf{2 5 \%}$ & $(\$ 6,067)$ \\
Skewness & -0.462419345 & $\mathbf{3 0 \%}$ & $(\$ 5,471)$ \\
Kurtosis & 3.169567001 & $\mathbf{3 5 \%}$ & $(\$ 4,931)$ \\
Median & $(\$ 3,534)$ & $\mathbf{4 0 \%}$ & $(\$ 4,443)$ \\
Mode & $(\$ 3,495)$ & $\mathbf{4 5 \%}$ & $(\$ 3,978)$ \\
Left X & $(\$ 10,310)$ & $\mathbf{5 0 \%}$ & $(\$ 3,534)$ \\
Left P & $5 \%$ & $\mathbf{5 5 \%}$ & $(\$ 3,110)$ \\
Right X & $\$ 1,445$ & $\mathbf{6 0 \%}$ & $(\$ 2,681)$ \\
Right P & $95 \%$ & $\mathbf{6 5 \%}$ & $(\$ 2,250)$ \\
Diff X & $\$ 11,755$ & $\mathbf{7 0 \%}$ & $(\$ 1,804)$ \\
Diff P & $90 \%$ & $\mathbf{7 5 \%}$ & $(\$ 1,336)$ \\
\#Errors & 0 & $\mathbf{8 0 \%}$ & $(\$ 821)$ \\
Filter Min & Off & $\mathbf{8 5 \%}$ & $(\$ 233)$ \\
Filter Max & Off & $\mathbf{9 0 \%}$ & $\$ 476$ \\
\#Filtered & 0 & $\mathbf{9 5 \%}$ & $\$ 1,445$ \\
\hline
\end{tabular}

\begin{tabular}{|l|l|l|l|}
\hline \multicolumn{4}{|l|}{ Regression and Rank Information for Key Inputs } \\
\hline Rank & Name & Regr & Corr \\
\hline 1 & Fuel Price per Gallon: & -0.584 & -0.584 \\
2 & Discount Rate: & 0.538 & 0.525 \\
3 & Battery Pack Cost (\$/kWh) $)$ & 0.464 & 0.472 \\
4 & Electricity Price/kWh & 0.185 & 0.137 \\
5 & Avg. Conventional MPG: & 0.171 & 0.153 \\
6 & Miles Driven Per Year: & -0.168 & -0.146 \\
7 & Conventional Maintenance & -0.147 & -0.139 \\
8 & EV Maintenance Costs per & 0.073 & 0.066 \\
9 & Level II Charging Plug Cost: & 0.042 & 0.042 \\
& & & \\
& & & \\
& & & \\
& & & \\
& & & \\
& & &
\end{tabular}




\section{Simulation Output for Cost Differential with Conventional Car / PHEV}

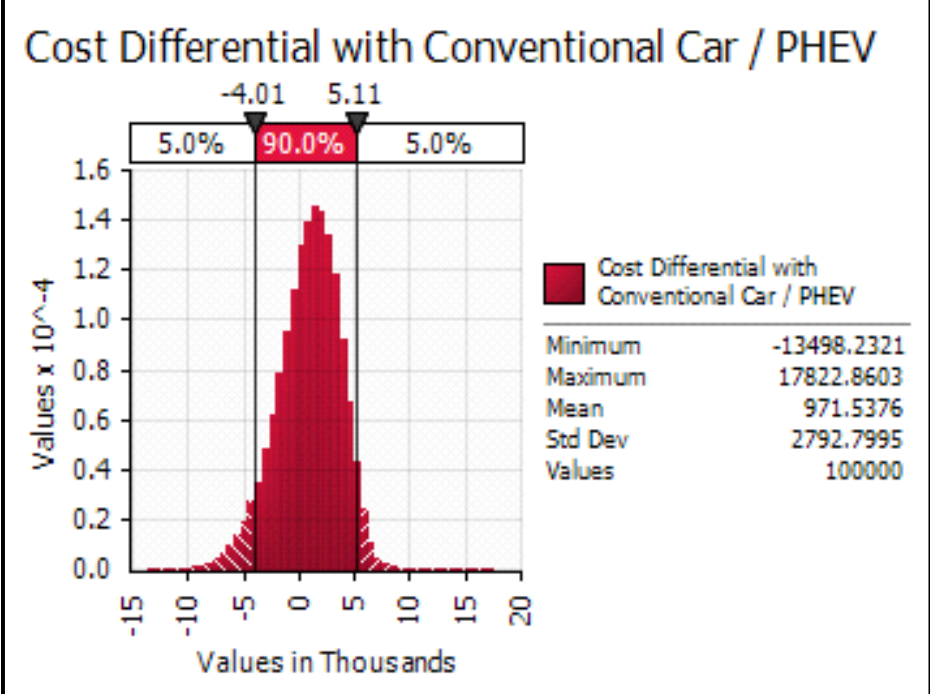

\section{Cost Differential with Conventional Car / PHEV}

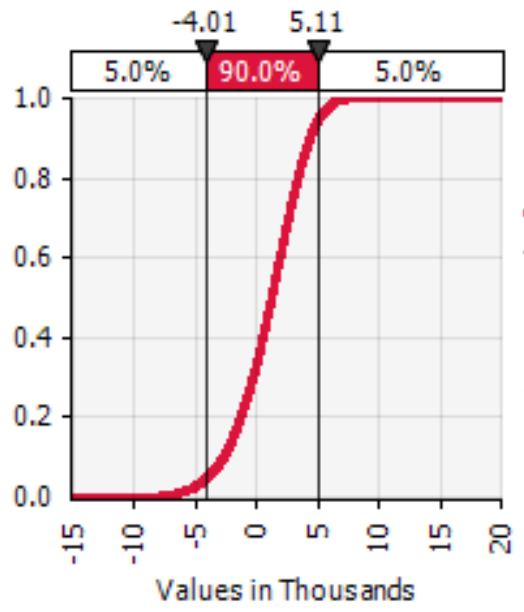

Cost Differential with - Conventional Car / PHEV Minimum $\quad-13498.2321$ Maximum $\quad 17822.8603$ Mean 971.5376 Std Dev $\quad 2792.7995$ Values 100000

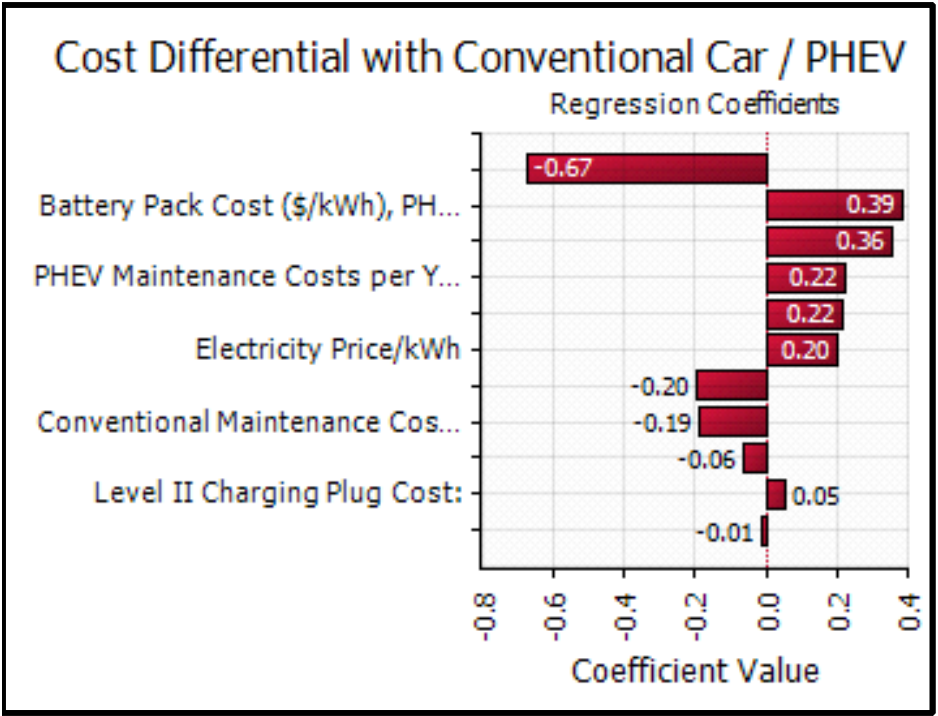

Summary Statistics for PHEV Cost Differential

\begin{tabular}{|l|l|r|l|}
\hline \multicolumn{2}{|l|}{ Statistics } & \multicolumn{2}{|l|}{ Percentile } \\
\hline Minimum & $(\$ 13,498)$ & $\mathbf{5 \%}$ & $(\$ 4,014)$ \\
Maximum & $\$ 17,823$ & $\mathbf{1 0 \%}$ & $(\$ 2,745)$ \\
Mean & $\$ 972$ & $\mathbf{1 5 \%}$ & $(\$ 1,929)$ \\
Std Dev & $\$ 2,793$ & $\mathbf{2 0 \%}$ & $(\$ 1,305)$ \\
Variance & 7799729.231 & $\mathbf{2 5 \%}$ & $(\$ 773)$ \\
Skewness & -0.458344807 & $\mathbf{3 0 \%}$ & $(\$ 315)$ \\
Kurtosis & 3.284463921 & $\mathbf{3 5 \%}$ & $\$ 107$ \\
Median & $\$ 1,208$ & $\mathbf{4 0 \%}$ & $\$ 484$ \\
Mode & $\$ 1,105$ & $\mathbf{4 5 \%}$ & $\$ 858$ \\
Left X & $(\$ 4,014)$ & $\mathbf{5 0 \%}$ & $\$ 1,208$ \\
Left P & $5 \%$ & $\mathbf{5 5 \%}$ & $\$ 1,551$ \\
Right X & $\$ 5,110$ & $\mathbf{6 0 \%}$ & $\$ 1,895$ \\
Right P & $95 \%$ & $\mathbf{6 5 \%}$ & $\$ 2,239$ \\
Diff X & $\$ 9,125$ & $\mathbf{7 0 \%}$ & $\$ 2,596$ \\
Diff P & $90 \%$ & $\mathbf{7 5 \%}$ & $\$ 2,971$ \\
$\#$ \#rrors & 0 & $\mathbf{8 0}$ & $\$ 3,363$ \\
Filter Min & Off & $\mathbf{8 5 \%}$ & $\$ 3,815$ \\
Filter Max & Off & $\mathbf{9 0 \%}$ & $\$ 4,358$ \\
\#Filtered & 0 & $\mathbf{9 5 \%}$ & $\$ 5,110$ \\
\hline
\end{tabular}

Regression and Rank Information for Key Inputs

\begin{tabular}{|l|l|l|l|}
\hline Rank & Name & Regr & Corr \\
\hline 1 & Fuel Price per Gallon: & -0.674 & -0.690 \\
2 & Battery Pack Cost (\$/kWh), & 0.388 & 0.393 \\
3 & Discount Rate: & 0.358 & 0.336 \\
4 & PHEV Maintenance Costs p & 0.224 & 0.223 \\
5 & Avg. Conventional MPG: & 0.218 & 0.193 \\
6 & Electricity Price/kWh & 0.200 & 0.150 \\
7 & Miles Driven Per Year: & -0.198 & -0.175 \\
8 & Conventional Maintenance & -0.187 & -0.176 \\
9 & Percent of PHEV miles drivg & -0.063 & -0.056 \\
10 & Level II Charging Plug Cost: & 0.053 & 0.051 \\
11 & Avg. HEV/PHEV MPG using & -0.015 & -0.013 \\
& & & \\
& & &
\end{tabular}




\section{Simulation Output for Cost Differential with Conventional Car / HEV}
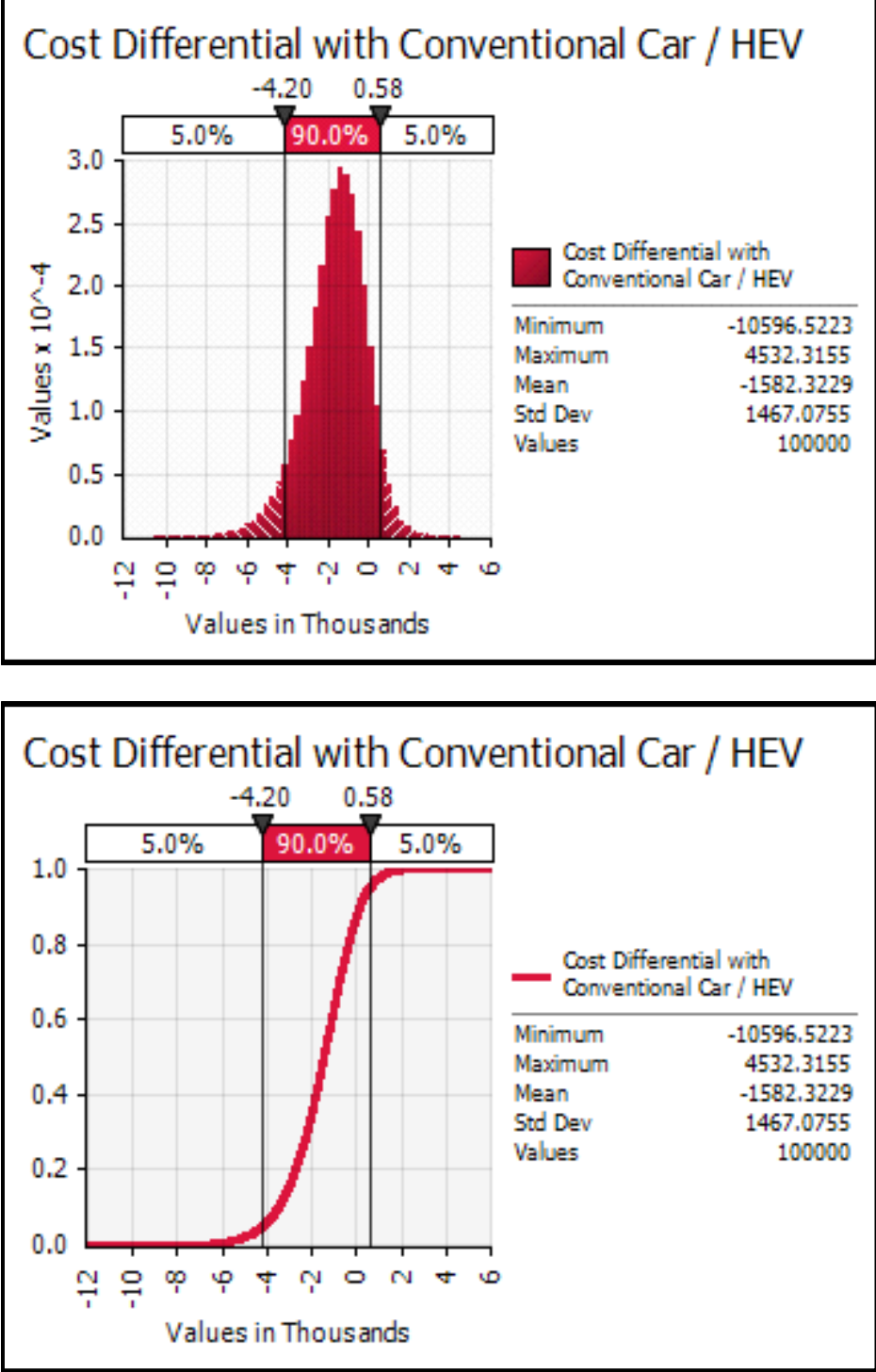

Cost Differential with Conventional Car / HEV

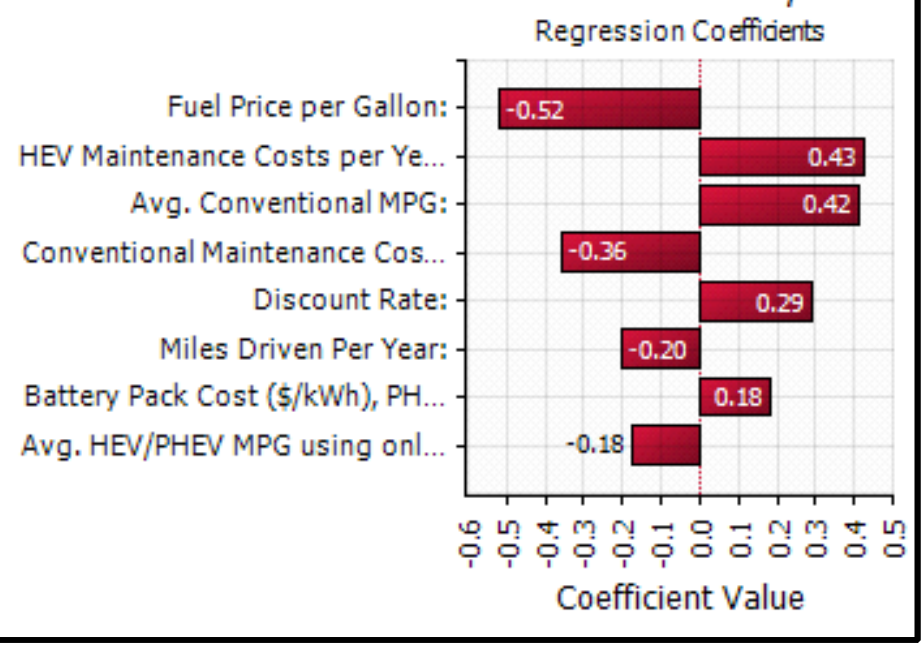

\begin{tabular}{|l|l|}
\hline \multicolumn{2}{|l|}{ Simulation Summary Information } \\
\hline Number of Simulations & 1 \\
Number of Iterations & 100000 \\
Number of Inputs & 14 \\
Number of Outputs & 3 \\
Sampling Type & Latin Hypercube \\
Random \# Generator & Mersenne Twister \\
Random Seed & 1981150932 \\
& \\
\hline
\end{tabular}

Summary Statistics for HEV Cost Differential

\begin{tabular}{|l|l|r|l|}
\hline \multicolumn{2}{|l|}{ Statistics } & \multicolumn{2}{|l|}{ Percentile } \\
\hline Minimum & $(\$ 10,597)$ & $\mathbf{5 \%}$ & $(\$ 4,199)$ \\
Maximum & $\$ 4,532$ & $\mathbf{1 0 \%}$ & $(\$ 3,509)$ \\
Mean & $(\$ 1,582)$ & $\mathbf{1 5 \%}$ & $(\$ 3,064)$ \\
Std Dev & $\$ 1,467$ & $\mathbf{2 0 \%}$ & $(\$ 2,730)$ \\
Variance & 2152310.638 & $\mathbf{2 5 \%}$ & $(\$ 2,452)$ \\
Skewness & -0.515133305 & $\mathbf{3 0 \%}$ & $(\$ 2,217)$ \\
Kurtosis & 3.684076543 & $\mathbf{3 5 \%}$ & $(\$ 2,007)$ \\
Median & $(\$ 1,456)$ & $\mathbf{4 0 \%}$ & $(\$ 1,813)$ \\
Mode & $(\$ 1,472)$ & $\mathbf{4 5 \%}$ & $(\$ 1,631)$ \\
Left X & $(\$ 4,199)$ & $\mathbf{5 0 \%}$ & $(\$ 1,456)$ \\
Left P & $5 \%$ & $\mathbf{5 5 \%}$ & $(\$ 1,286)$ \\
Right X & $\$ 582$ & $\mathbf{6 0 \%}$ & $(\$ 1,116)$ \\
Right P & $95 \%$ & $\mathbf{6 5 \%}$ & $(\$ 940)$ \\
DiffX & $\$ 4,781$ & $\mathbf{7 0 \%}$ & $(\$ 763)$ \\
Diff P & $90 \%$ & $\mathbf{7 5 \%}$ & $(\$ 574)$ \\
\#Errors & 0 & $\mathbf{8 0 \%}$ & $(\$ 367)$ \\
Filter Min & Off & $\mathbf{8 5 \%}$ & $(\$ 137)$ \\
Filter Max & Off & $\mathbf{9 0 \%}$ & $\$ 152$ \\
\#Filtered & 0 & $\mathbf{9 5 \%}$ & $\$ 582$ \\
\hline
\end{tabular}

Regression and Rank Information for Key Inputs

\begin{tabular}{|l|l|l|l|}
\hline Rank & Name & Regr & Corr \\
\hline 1 & Fuel Price per Gallon: & -0.519 & -0.525 \\
2 & HEV Maintenance Costs pe & 0.428 & 0.417 \\
3 & Avg. Conventional MPG: & 0.415 & 0.391 \\
4 & Conventional Maintenance & -0.356 & -0.344 \\
5 & Discount Rate: & 0.291 & 0.274 \\
6 & Miles Driven Per Year: & -0.201 & -0.181 \\
7 & Battery Pack Cost (\$/kWh) $)$ & 0.182 & 0.181 \\
8 & Avg. HEV/PHEV MPG using & -0.176 & -0.158 \\
& & & \\
& & & \\
& & & \\
& & & \\
& & &
\end{tabular}




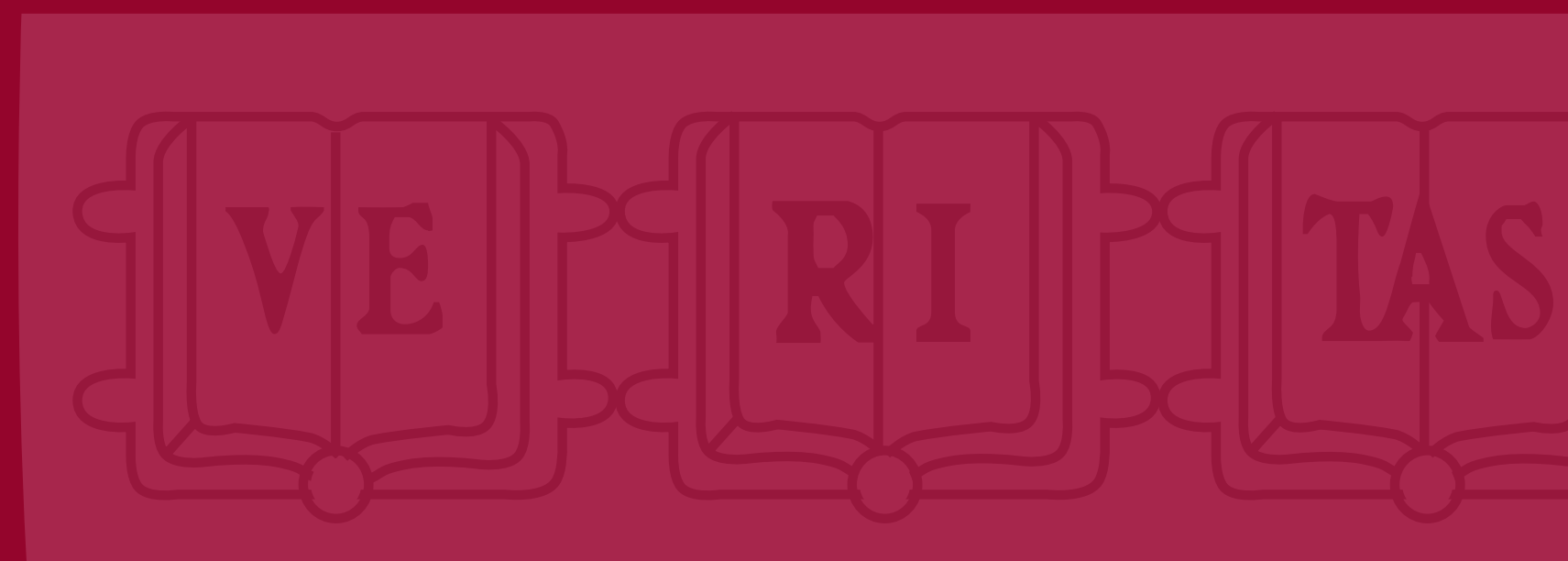

\section{Belfer Center for Science and International Affairs}

Harvard Kennedy School

79 JFK Street

Cambridge, MA 02138

Fax: (617) 495-8963

Email: belfer_center@harvard.edu

Website: http://belfercenter.org

Copyright 2011 President and Fellows of Harvard College 